University of San Diego

Digital USD

2014-05-01

\title{
A Phenomenological Study of Acceptability of Preexposure Prophylaxis Therapy within the Lived Experiences of HIV Negative Male-to-Female Transgender Young Adults
}

Gloria N. Nwagwu PhD

University of San Diego

Follow this and additional works at: https://digital.sandiego.edu/dissertations

Part of the Nursing Commons

\section{Digital USD Citation}

Nwagwu, Gloria N. PhD, "A Phenomenological Study of Acceptability of Preexposure Prophylaxis Therapy within the Lived Experiences of HIV Negative Male-to-Female Transgender Young Adults" (2014).

Dissertations. 460.

https://digital.sandiego.edu/dissertations/460

This Dissertation: Open Access is brought to you for free and open access by the Theses and Dissertations at Digital USD. It has been accepted for inclusion in Dissertations by an authorized administrator of Digital USD. For more information, please contact digital@sandiego.edu. 


\section{UNIVERSITY OF SAN DIEGO}

Hahn School of Nursing and Health Sciences

DOCTOR OF PHILOSOPHY IN NURSING

A Phenomenological Study Of Acceptability Of Preexposure Prophylaxis Therapy Within The Lived Experiences Of HIV Negative Male-To-Female Transgender Young Adults

By

Gloria N Nwagwu, RN, PhD

A dissertation presented to the

FACULTY OF THE HAHN SCHOOL OF NURSING AND HEALTH SCIENCES

UNIVERSITY OF SAN DIEGO

In partial fulfillment of the requirements for the degree

DOCTOR OF PHILOSOPHY IN NURSING

May 2014

DISSERTATION COMMITTEE

Dr. Jane Georges, PhD, RN, Chairperson

Dr. Ann M. Mayo, DNSc, RN, FAAN

Dr. Cynthia Connelly, PhD, RN, FAAN 
(C) Gloria Nwagwu

All Rights Reserved 2014 


\begin{abstract}
A Phenomenological Study Of Acceptability Of Pre-Exposure Prophylaxis Within The Lived Experiences Of HIV Negative Male-To-Female Transgender Young Adults

The male-to-female transgender (MtF-TG) are individuals assigned a male gender at birth but self identify as female. MtF-TG young adults experience discrimination, stigmatization, isolation, and homelessness as a result of gender identity and gender expression. The transgender populations are linked to high rate of new HIV infection. The use of Preexposure prophylaxis (PrEP) therapy demonstrated a decrease in HIV infection risk ranging from $42 \%$ to $73 \%$ among sexual minority individuals. The goal of this three-part study was achieved through concept analysis, data collection, and analysis. The following aims were addressed; analyze the concept of transgender, explore currently used HIV prevention practices and knowledge of PrEP therapy, explore the potential of acceptability of PrEP therapy, and explore facilitators and barriers to acceptance of PrEP therapy. The findings resulted in three manuscripts: Transgender: Concept Analysis focused on analysis of the concept of transgender; A Phenomenological Study of Acceptability of Preexposure Therapy within the Lived Experiences of HIV Negative Male-To-Female Transgender young Adults utilized in-depth semi-structured interviews of 15 self-identified HIV negative MTF-TG young adults and Colaizzi's seven steps of data analysis to identify related themes; It's Deal Breaker: Safe Sex Practices Among Homeless Male-To-Female Young Adults focused on thematic findings of secondary results of primary study. Thematic findings were attributes of MtF-TG, essence of life as MtF-TG, motivators and barriers for PrEP acceptability. Findings have potential to inform practice, policy changes, and future research.
\end{abstract}


Key Words: male-to-female transgender (MtF-TG), phenomenology, transgender, gender dysphoria, transwomen 


\section{DEDICATION}

First, I will like to dedicate this dissertation to Almighty God without whom none of it could have been possible. Secondly, this work is dedicated to my mother who was the rock of our family. I thank you mom for teaching me to believe in myself, and letting me know that only I can stop me from reaching my desired goals. I wish you waited to see me reach that goal. Mom passed away on April 09, 2014. Thirdly, this is for my wonderful children: Johnny, Judith, Jeanne, and Jacquelyn. Thank you for your support and interest in my work. Each one of you deserve accolades for you unique supports: Johnny for being my unpaid editor, Judith for encouraging me, Jeanne for letting me know brighter days are ahead, and Jacquelyn for always reminding me to write my paper. This is for all four of you. 


\section{ACKNOWLEDGMENTS}

Many people walked with me on this journey to obtain a doctorate studies and complete this dissertation. Mr. and Mrs. Odinachi, thank you for adopting the kids and me and for all your support through this journey. To all of my brothers and sisters, thank you for being my cheerleaders.

I want to thank the entire faculty and staff at USD School of Nursing for sharing your knowledge with me. Dr. Clark I am grateful for you teaching me how to write for publication and your interest in my work.

I would like to express my utmost gratitude to my dissertation committee members. Dr. Georges from the day you agreed to be my Chairperson, you worked diligently to mold and help direct my qualitative research skills. You are a rare gem that radiates hope and confidence at all times. Thank you for believing in me enough for me to believe that I could complete this journey. Dr. Mayo, I am grateful for your time and your willingness to participate in my final defense. Thank you for the many revisions. Dr. Connelly, thank you for your role as dissertation committee member and your contribution to my doctorate education.

I would like to express my gratitude to all of the participants for their willingness to share their life stories with me. I am honored and humbled by your lived experiences.

Last but not the least; I would like to thank my two classmates, friends and sisters as we call ourselves. Thank you for being there and allowing me to be a part of you. 


\section{TABLE OF CONTENTS}

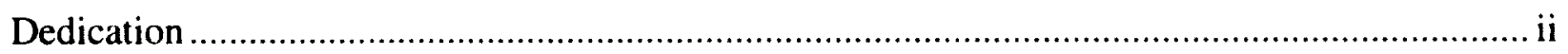

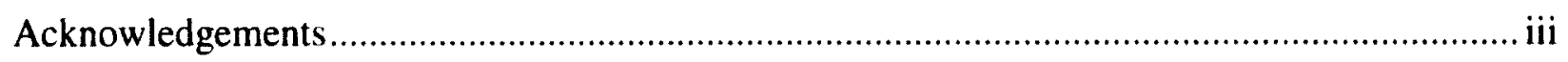

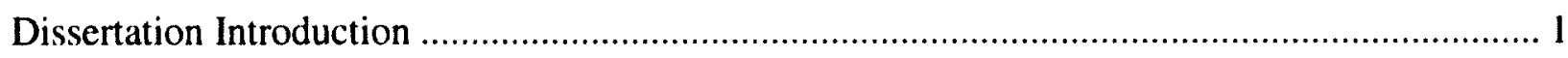

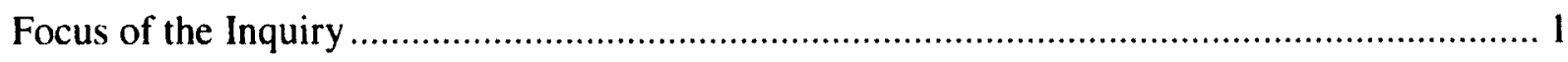

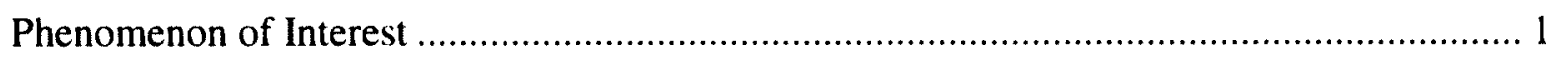

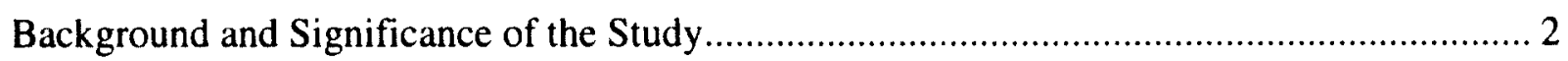

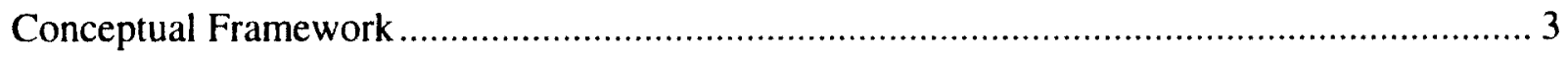

The Socio-Ecological Context of Male-to-Female Transgender Youths ................................ 4

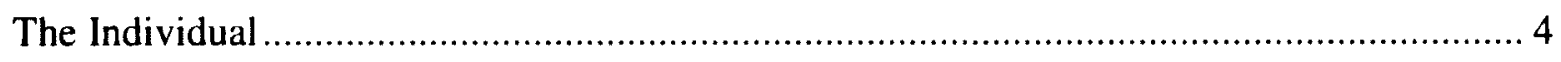

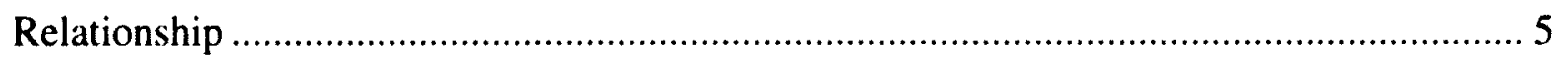

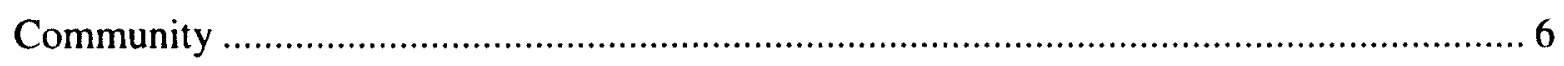

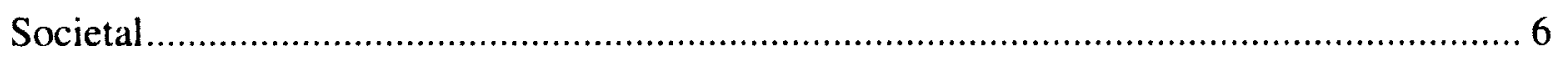

Philosophical Under Pinning of Descriptive Phenomenological Study .................................... 7

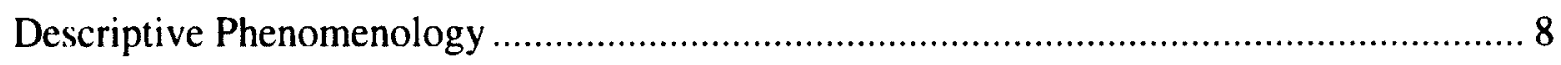

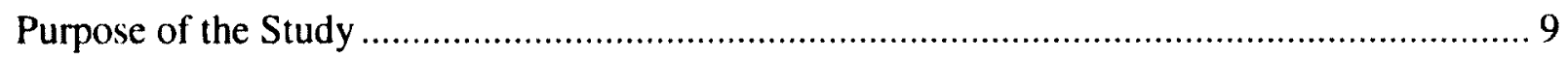

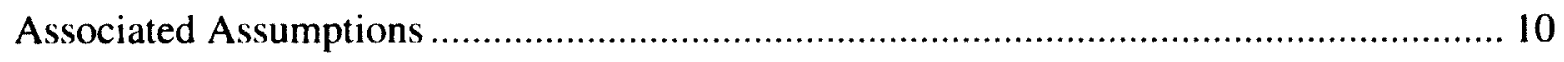

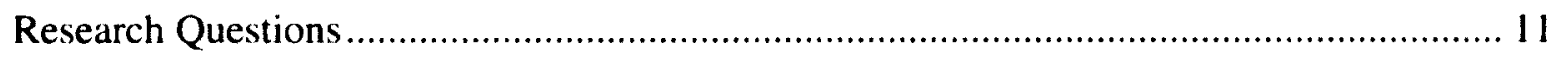

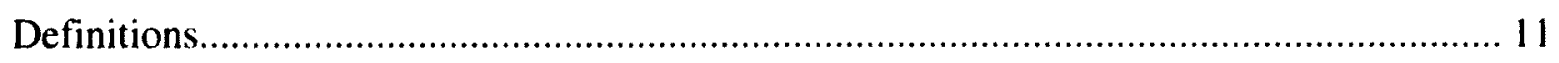

Summary

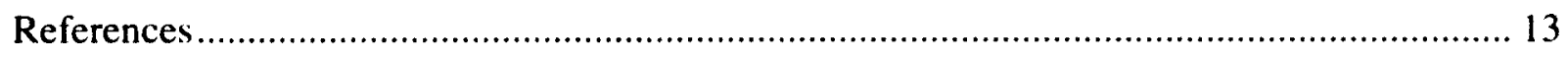

Manuscript \# 1. Transgender: A Concept Analysis ............................................................... 18 


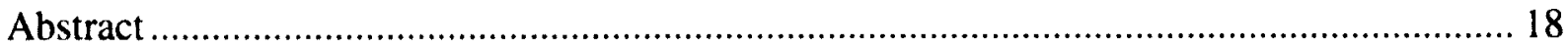

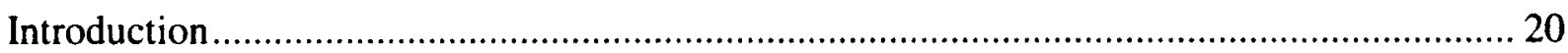

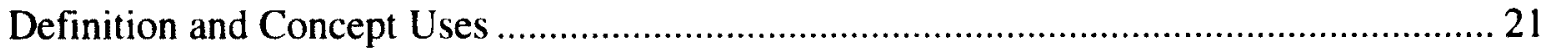

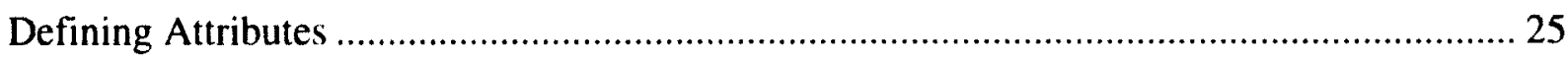

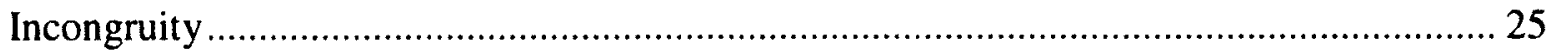

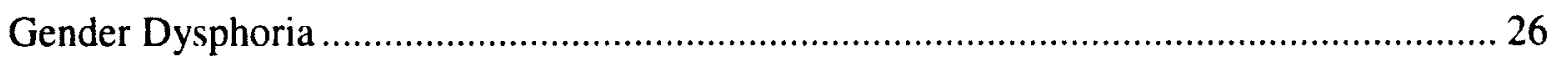

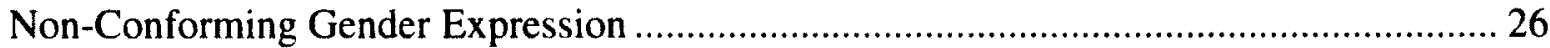

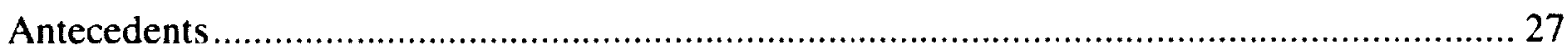

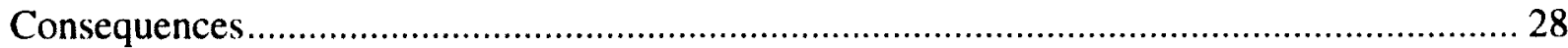

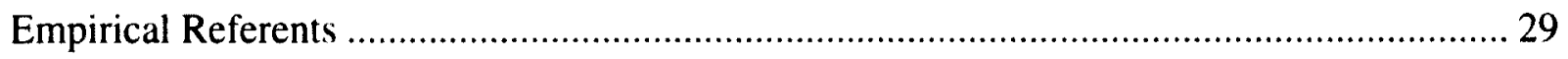

Cases

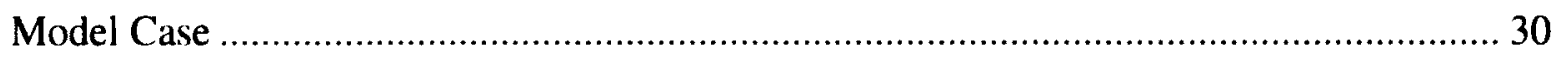

Borderline Case

Contrary Case

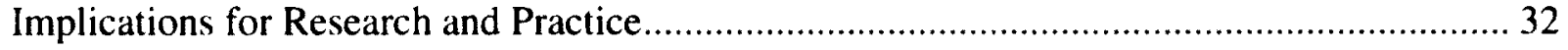

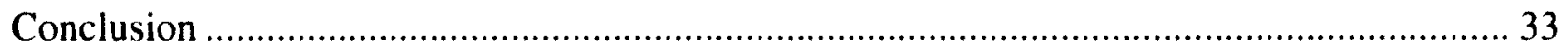

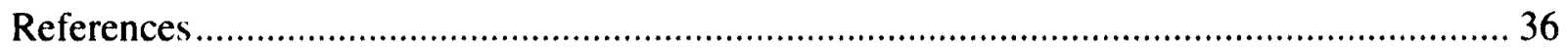

Manuscript 2. A Phenomenological Study Of Acceptability Of Pre-Exposure Prophylaxis

Within The Lived Experiences Of HIV Negative Male-To-Female Transgender Young

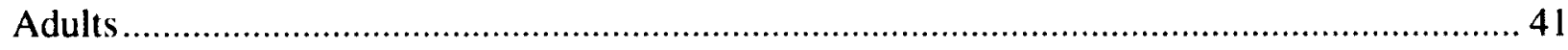

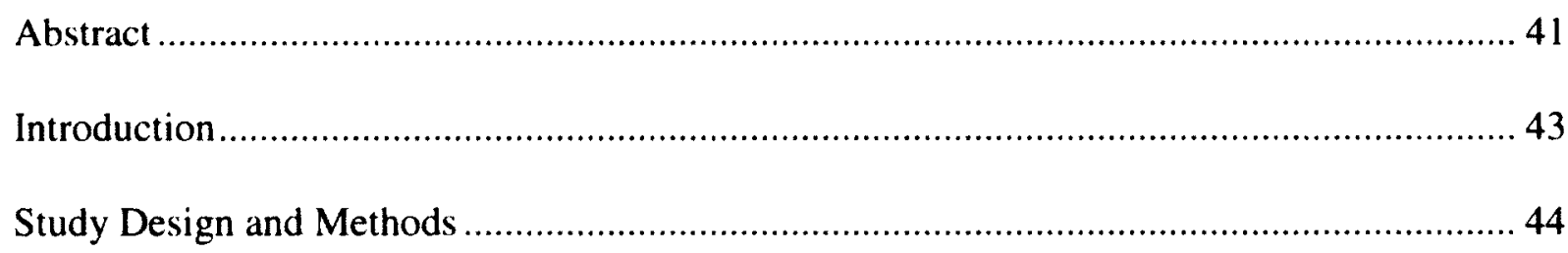


Results 46

Attributes of Male-To-Female Transgender (MtF-TG) ………........................................ 47

Essence of Life as a Male-To Female Transgendered Individual....................................... 50

Motivators for Acceptability of Preexposure Prophylaxis Therapy ..................................... 52

Barriers To Acceptability of Preexposure Prophylaxis Therapy ......................................... 54

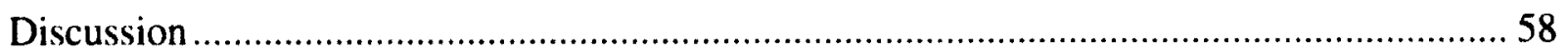

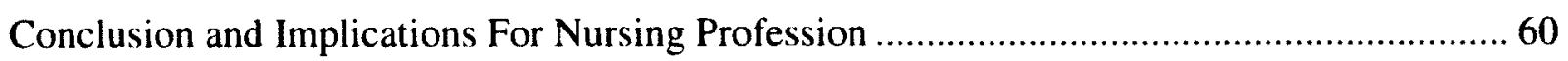

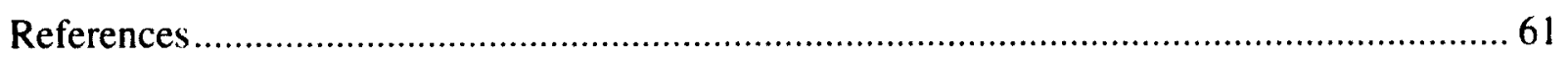

Manuscript 3. It's a Deal Breaker: Safe Sex Practice Among Homeless Male-to-Female

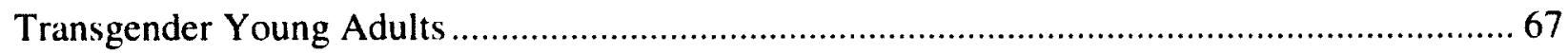

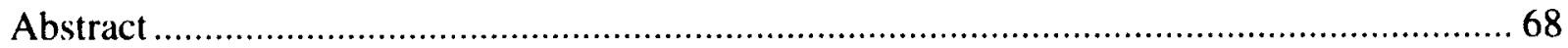

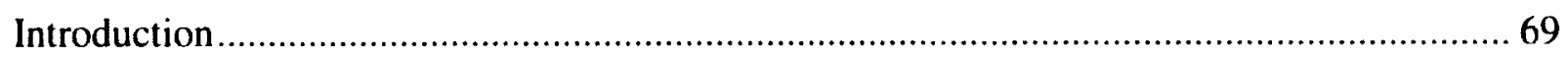

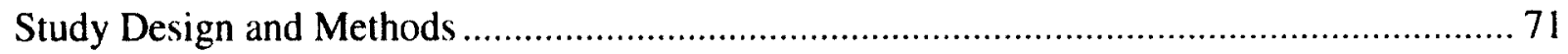

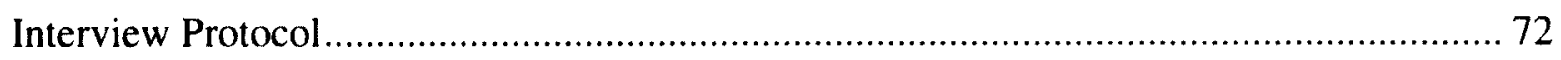

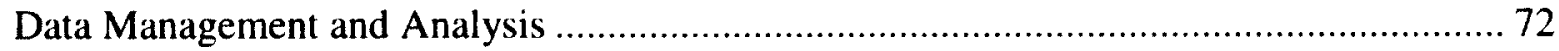

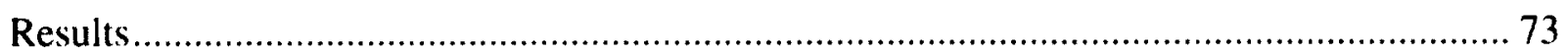

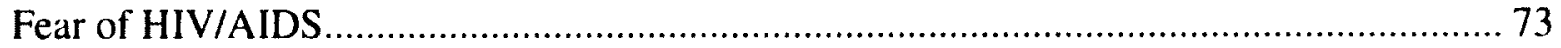

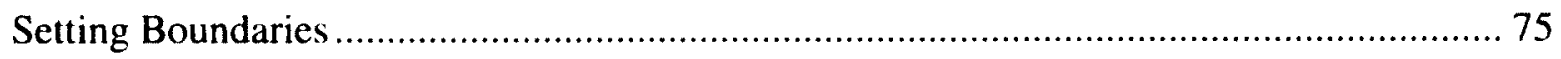

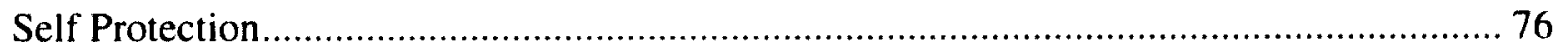

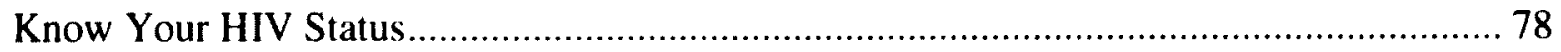

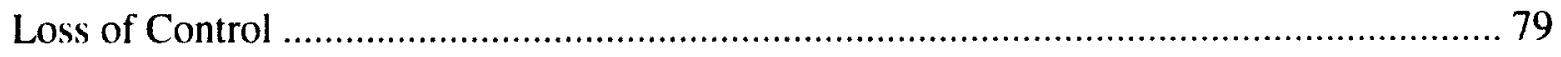

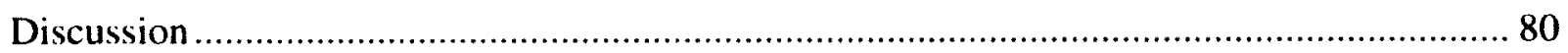

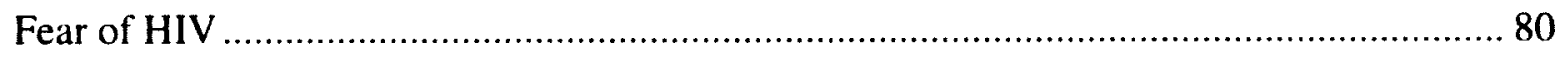




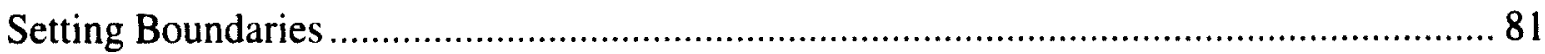

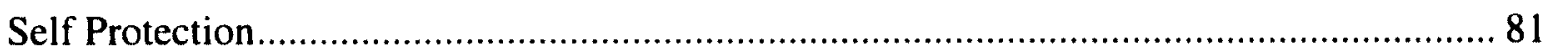

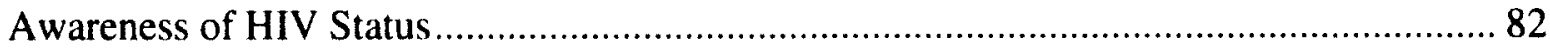

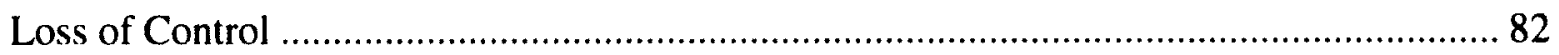

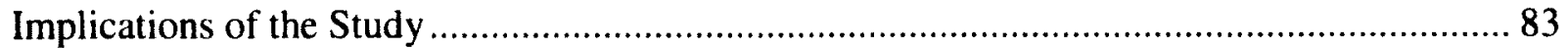

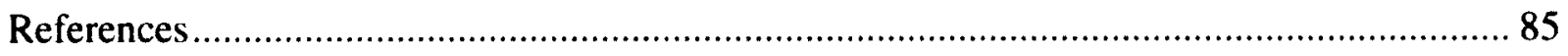

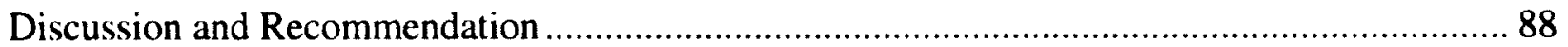

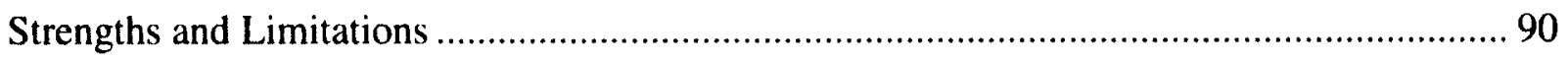

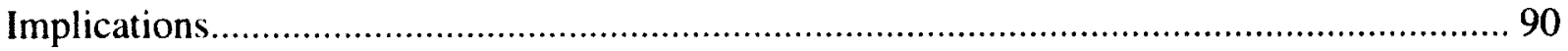

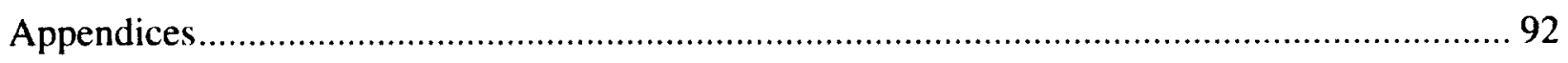

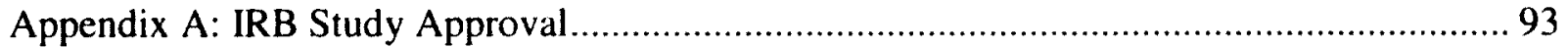

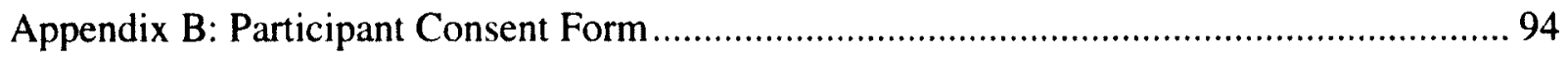

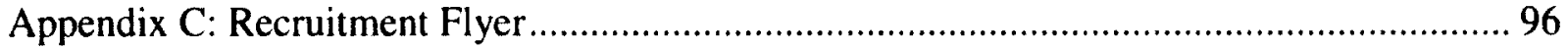

Appendix D: Qualitative Interview Questionnaires: Structured and Unstructured .................. 97 
Dissertation Introduction

\section{Focus of the Inquiry}

Pre-exposure prophylaxis, or $\operatorname{PrEP}$, is a new HIV prevention method in which people who do not have HIV infection take a pill daily to reduce their risk of becoming infected. The pill contains medicines that prevent HIV from making new virus as it enters the body. In this way PrEP medicines can help keep the virus from establishing a permanent infection (CDC, 2012).

\section{Phenomenon of Interest}

Transgender is an umbrella term used to describe individuals who fail to conform to the culturally accepted dichotomy of male and female gender (Conron, Scott, Stowell, \& Landers, 2012; Garofalo et al., 2006; Keatley \& Bockting, 2008). These individuals are frequently marginalized and rejected for being different based on their gender and sexual identity. The male-to-female transgender (MtF-TG) constitutes a sub-group of the transgender population. They experience discordance between anatomically assigned sex at birth and self identified gender identity as opposite gender. They have a strong affinity to be female and exhibit female characteristics to the disapproval of the family, peers, and the community (Conron et al., 2012).

Gender expression and gender identity are often the cause for rejection and discrimination by families, peers and community at the critical period of adolescent development when family support is crucial to self-discovery and affirmation. Previous studies indicate that homophobia and rejection contribute to the physical, psychological, 
and mental health issues reported by transgendered population (Diaz, Ayala, Bein, Henne, \& Marin, 2001; Galindo, 2013; Garofalo et al., 2006, Gate, 2011). MtF-TG young adults are victims of homelessness, isolation, verbal and sexual violence, and discrimination with consequential lack of education and acquisition of basic life skills. 


\section{Background and Significance of the Study}

Many MtF-TG young adults experience a double minority status by virtue of being transgendered and a member of the LGBT community. The culmination of multi-level stressors of dissociation from families, perceived stigma, and discrimination have also been linked to substance abuse, survival sex, and reluctance to access health care resources (Stevens, Bernadini, \& Jemmott, 2013). MtF-TG individuals engage in HIVrisk behaviors and prostitution that constitutes public health risk since they account for the highest new HIV infection rate (Conron, Scott, Stowell, \& Landers, 2012; DHAP, 2011; Galindo, 2013; Garofalo, Deleon, Osmer, Doll, \& Harper, 2006). Environmental stressors resulting from isolation, depression, and discrimination during adolescence compounds gender dysphoria among MtF-TG young adults (Garofalo, Osmer, Sullivan, Doll, \& Harper, 2006). These factors are predictors of engaging in high-risk sexual behaviors, with potential for HIV-infection (Garofalo et al., 2006; Garofalo, Osmer, Sullivan, Doll, \& Harper, 2006).

Prior to 2012, different approaches were explored and implemented to address the issue of HIV among MtF-TG individuals, including the high impact prevention project implemented by the Center for Disease Control (CDC) and its partners to augment existing approaches of education regarding safe sex and HIV testing campaigns (CDC, 2013). In 2012, the USFDA approved the use of a combination of tenofovir and emtricitabine (Truvada ${ }^{\circledR}$ ) as a pre-exposure chemoprophylaxis (PrEP) method for HIV prevention among high-risk population groups (CDC, 2012). Truvada has been in use since 2004 for treatment of HIV; however, a new application of its use was introduced following promising results of the investigation for the Pre-Exposure Prophylaxis 
Initiatives (iPrEX) indicating $44 \%$ efficacy HIV prevention among HIV negative men who have sex with men (MSM) and MtF-TG (CDC, 2012; Grant et al., 2010). Other studies documented higher efficacies of $63-73 \%$ of HIV prevention among HIV negative sexual minorities when combined with behavioral prevention methods (Grant et al., 2010). In some studies where high incidence of medication administration compliance was observed, there was evidence of potential for a higher rate of HIV prevention with $\operatorname{PrEP}(\mathrm{CDC}, 2011)$.

In 2012, the USFDA approved the use of pre-exposure prophylaxis therapy (PrEP) chemotherapy in the form of a combination of two anti-retroviral medications, formally known as Truvada, for HIV prevention among high-risk groups of men who have sex with men (MSM) and transgendered individuals who are HIV negative. PrEP as a daily oral medication has the potential to prevent HIV infection (Grant et al., 2010). While there is strong evidence indicating the efficacy of PrEP among adult MSM and transgender individuals, there are challenges in the implementation of this therapy.

Currently, no known published study has utilized the phenomenological method to describe the acceptability of PrEP therapy as a preventive method within the context of the lived experiences of the HIV negative MtF-TG population ages 18-25. Knowledge generated from this study would add to the extant literature on the successful implementation of PrEP among HIV vulnerable populations, and create a basis for future intervention design, policy change, and future research concerning target population.

\section{Conceptual Framework}

Bronfenbrenner (1977) socio-ecological model was appropriate this study, since it posits a relationship between the individual and different levels of the environment 
influences health outcomes. This study is based on the assumption of the social ecological module that speaks to the reciprocal relationship between the environment, family, school, and community on adolescents' health outcomes (Bronfenbrenner, 1977). The Socio-Ecological Context of Male-to-Female Transgender Youths

An examination of the interrelated influences operating on various system levels during the development of MtF-TG young adults provides a basis for exploration of their lived experiences, available resources, and predisposing factors to high-risk sexual behaviors. Most adolescents, given a supportive family and adequate resources, have the potential to mature into well-adjusted adults. MtF-TG young adults often experience a of lack family support, are frequently homeless, and are the recipients of discrimination from family, peers, community and society. Subsequently, many are victims of verbal, physical, sexual abuse, with lower educational levels resulting in homelessness. Often, sex work becomes their only means for survival (DHAP, 2011). Understanding of the interactions between environmental and psychosocial factors that influence access to resources can enhance understanding of the challenges within MtF-TG young adults' lived experiences.

\section{The Individual}

MtF-TG young adults are situated in an environment of rejection and discrimination. The unhealthy environments are precursors to self-isolation, unemployment, and substance, physical, and mental abuse (DHAP, 2011). The MtF-TG population struggles with gender dysphoria associated with their assigned sex at birth, subsequent gender identification, and social stigma and discrimination within their own 
group. Navigating MtF-TG young adults' risk-landscape within the context of rejection and discrimination is a difficult challenge.

\section{Relationship}

A higher level of family acceptance predicts higher levels of self-esteem, social support, and general well being of physical and mental health as well decreased suicidal ideations, depression, high-risk behaviors, low education, and substance abuse (Caitlin, 2009; Garofalo et al., 2006; Grossman \& D'augelli, 2006). Frequently, the existing conflicts in the primary family culminate in young adults being disowned, rejected, and sent away from home or the individual running away for self protection (Ream, Barnhart, \& Lotz, 2012). Transgender and sexual minority young adults exposed to a lack of parental support, negative social environment of rejection, verbal and physical abuse, shame and discrimination are: (a) more than 8 times more likely to attempt suicide; (b) about 6 times more likely to report high levels of depression; (c) more than three times more likely to use illegal drugs; and (d) more than three times likely to be at high risk for HIV/AIDS (Caitlin (2009).

According to a national survey by the Gay, Lesbian, and Straight Education network (GLSEN), 22\% of LGBT young adults reported feeling unsafe at school in relation to bulling and physical abuse. Compared to $62 \%$ of non-LGBT young adults, $90 \%$ confirmed being harassed or physically abused in the previous school year (Bostwick, 2007; Vargas et al., 2008). Within the school system, MtF-TG young adults experienced harassment, bullying, physical violence, rejections, discriminations, and stigma from peers and teachers (Kosciw, Greytalk, \& Diaz, 2009). The hostile environment is thus a precursor to transgender young adults being displaced from home 
on to the street, shelters, or juvenile centers where they turn to peers and social networks for friendship and support.

\section{Community}

The MtF-TG individuals displaced from home are subjected to further life stressors in the community. The societal lack of understanding of the concept of transgender is contributory to societal stigma, continued verb and physical abuse, discrimination, low education, lack of employment, and lack of access to both medical and mental health (Bith-Melander et al., 2012; Garofalo et al., 2006; Kosciw et al., 2009). As a class of marginalized people, these individuals experience homelessness, poor education, unemployment, and engagement in survival sex work to afford basic needs (Logie, James, Tharao, \& Loutfy, 2011; Stevens, Bernadini, \& Jemmott, 2013). Perceived and internalized stigma predisposes sexual minority individuals to low selfesteem, self-isolation, and unwillingness to seek or access necessary social needs, including HIV testing and treatment. As a means of self-preservation and better navigation of their risk-landscape against discrimination and stigma, many MtF-TG young adults practice partner selection and, paradoxically, non-participation in HIV testing creating a complex public health issue.

\section{Societal}

Some religious beliefs and cultural values present in contemporary North America have created a hostile environment of shame and misunderstanding regarding sexual minority groups, including the transgender population. Societal racism, perceived stigma, homophobia, transphobia, and discrimination against sexual minorities are contributory factors to depression, anxiety, and suicidal ideation (Bostwick, 2007; Burgess, 2000; 
Caitlin, 2009; \& Garofalo et al., 2006). MtF-TG young adults have reported lack of support, discrimination, violence, and abuse by mental health care providers, social workers as well as counselors compounding issues of low self-esteem and psychological health. Health care providers are perceived as barriers to access to health care system by MtF-TG individuals; hence they seek illegal sources on the streets for feminization drugs (Grossman \& D'augelli, 2006; Stieglitz, 2010).

\section{Philosophical Under Pinning of Descriptive Phenomenological Study}

Phenomenology is the study of essences; and according to it, all problems amount to finding definitions of essences: the essence of perception, or the essence of consciousness, for example. But phenomenology is also a philosophy, which puts essence back into existence, and does not expect to arrive at an understanding of man and the world from any starting point other than that of their 'facticity' (Merleau-Ponty, 2008).

Phenomenological study is concerned with the lived experience of participants and the meaning of the phenomenon of study to them (Polit \& Beck, 2012). Understanding the intra- and inter- relational influences of the socio-ecological systems within the lived experiences of MtF-TG young adults has the potential to shed light on emerging phenomena of their acceptability of PReP. Phenomenology, however, transcends description and moves into interpretation of the experiences to expose the meaning on the phenomenon of interest by the researcher (Creswell, 2013). Phenomenology is a qualitative methodological approach based on the philosophical underpinnings of various 20th century phenomenologists, including Husserl, Heidegger, Gorgi, and Van Manen. 
In general, phenomenological studies can be classified into Husserl's descriptive phenomenology, Heidegger's interpretative/hermeneutic phenomenology, and MerleauPonty's existentialist phenomenology (Holloway \& Wheeler, 2010). Each approach developed different steps to data collection and analysis to achieve the principles of grounding, reflexivity, and humanization (Holloway \& Wheeler, 2010). The different but overlapping philosophical movements that gave rise to the phenomenological method are typified by the philosophical views of the authors and their followers. The phenomenological movement began in Germany with Edmond Husserl's (1859-1938) descriptive phenomenology, followed by Martin Heidegger's (1889-1976) work in hermeneutic phenomenology. In France, the philosopher Merleau-Ponty (1908-1961) developed existentialist phenomenology, a movement expanded by Jean-Paul Sartre (1905-1980) (Holloway \& Wheeler, 2010). Husserl, however, is recognized universally as the principal figure that established the phenomenology movement.

\section{Descriptive Phenomenology}

The descriptive phenomenological method is the chosen approach for this study and is guided by the underpinnings of Merleau Ponty's philosophical views. Merleau Ponty expanded Edmund Husserl's descriptive phenomenology of essence to include a philosophy of existentialism. In Merleau Ponty's work, existentialist phenomenology views the individual as a body living in a preexisting world and having a reciprocate relationship with the world (Sadala \& Adorno, 2002). The focus of Merleau Ponty's method is to return to the essence of the object and their qualities within the context of the lived and experienced within a pre-existing world where the participant now unintentionally exists. "The existential phenomenology deals with human beings in the 
world within their condition of existing in a pregiven world and being limited by their condition, and their freedom to choose" (Sadala \& Adorno, 2002, p. 288). In this study, descriptive phenomenology through Merleau Ponty's philosophical lens afforded the researcher an opportunity to describe the lived experience of HIV negative MtF-TG youths within the context of the socio-ecological levels of their pregiven world and acceptability of PReP as HIV prevention method. The body of the HIV-negative MtF-TG individual was viewed as the link to the pregiven world, and any disturbance in this relationship subsequently is anticipated to affect the individual's health. A descriptive phenomenological approach was best suited for phenomena of MtF-TG and acceptability of PReP for prevention of HIV, as it provided "thick" views of the lived experience of a relatively unexplored phenomenon.

The method described by Walker and Avant (2011) was utilized to develop the concept analysis of transgender, describing its attributes, antecedents, consequences, and empirical referents as well as cases that further clarify the concept.

\section{Purpose of the Study}

The phenomenological study provided a much-needed knowledge base regarding the HIV-negative minority MTF-TG youth population's lived experiences of the issues surrounding acceptability of PReP therapy. When a phenomenon is poorly understood or relates to a lived experience, a descriptive phenomenological study approach is best adopted (Polit \& Beck, 2012). This type of study focuses on the meaning, direction, and purpose of the participants' lived experiences. A phenomenological study approach is 
paramount in exploring a phenomenon related to a special group or individuals sharing an experience as a basis for future policy or practice improvement change (Creswell, 2011).

The overall goals of this qualitative phenomenological study were to first define the concept of transgender; then describe acceptability of PrEP within the lived experiences of MtF-TG HIV negative young adults. The specific aims were: (a) define the concept of transgender; (b) describe facilitators and barriers to acceptance of PrEP therapy; (c) describe the acceptability of PrEP within the lived experiences of HIV negative male-to-female transgender young adults; and (d) explore current perceptions regarding HIV prevention, including HIV testing, currently used HIV prevention practices, and knowledge of pre-exposure prophylaxis therapy.

\section{Associated Assumptions}

The gender variant populations, including transgender young adults, are subjected to life-long stress associated with assumptions that being different from the societal binary gender of female and male is wrong. Subsequently, they are subjected to rejection from their family, peers, community, and society at large (Hunt \& Moodie-Mills, 2012). Being different is a contributory factor to the verbal, physical, and sexual abuse, stigma, and discrimination endured by the gender variant population. Based upon the widely held assumption that gender variance is a disease process or temporary state of psychological mental state that can be cured or changed, parents may subject transgender individuals to various treatment processes. Thus, transgender young adults may be forced to undergo to conversion processes and prayers by family members, and medications and psychotherapy from health care professionals. 
In addition, the justice system may label them as sexual deviants, resulting in institutionalization in juvenile facilities and the jail system. Unfortunately, because of these assumptions regarding gender variance, the transgender youths are separated from other youth both at school for their looks, sexual identity, gender identity, and sexual orientation, further impeding developmental socialization and adjustment to gender dysphoria (Hunt \& Moodie-Mills, 2012). Only a minority of MtF-TG youths with early strong family, peer, and community support meets the challenges posed by gender dysphoria, defy societal assumptions, and achieve a well-adjusted early adulthood.

\section{Research Questions}

This descriptive phenomenological study was guided by Merleau Ponty's existential philosophy that offers a referential conversation with participants to gather circumstantial descriptions of their lived experiences as HIV negative MtF-TG individuals to help answer the research questions (Holloway \& Wheeler, 2010). Colaizzi's seven steps for data analysis and answers for the following research questions guided the analysis of interview data: (a) what are your current perceptions regarding HIV prevention, including HIV testing and what HIV prevention practices do you use?

(b) What do you know about Preexposure prophylaxis therapy? (c) What are some facilitators and barriers to your acceptance of pre-exposure prophylaxis therapy? Additional probes were utilized to guide the line of inquiry for participants to reflect on the questions within their lived experiences and knowledge of HIV infection.

\section{Definitions}

For the purposes of this study, the following definitions were used. 
Transgender: An umbrella term used to describe the population that exhibits incongruence with birth sex and gender identity. Such individuals are non-conforming to the traditional binary gender of male and female.

Male-to-female (MtF): Individuals assigned as male at birth that make transitions to female either by use of hormones, sexual reassignment surgeries, or in some cases, no interventions.

Transwoman or transgender woman: A MtF-TG person with a female gender identity (CDC, 2011).

\section{Summary}

A clear understanding of the concept of transgender would facilitate practice implementations and health policy concerning sexual minority population. Enhanced knowledge about transgender individuals by health care providers would enhance health promotion and disease prevention among these vulnerable individuals. The successful implementation of PrEP among HIV-negative MtF-TG individuals would be augmented with increased knowledge of facilitators and barriers to adoption. Future research can focus on how to improve health outcomes of MtF-TG young adults based on knowledge of their challenges. Adoption of condom and other safe sex practices allow for expansion of structural HIV prevention among vulnerable minority populations. 


\section{References}

Bith-Melander, P., Sheoran, B., Sheth, L., Bermudez, C., Drone, J., Wood, W., \& Schroeder, K. (2012, May/June). Understanding Sociocultural And Psychological Factors Affecting Transgender People Of Color In San Francisco. Journal Of The Association Of Nurses In AIDS Care, 2I(3), 207-220. http://dx.doi.org/10.1016/j.jana2010.01.008

Bostwick, W. B. (2007). Mental Health Risk Factors Among GLBT Youth. Retrieved from http://www.nami.org/TextTemplate.cfm?Section=Fact_Sheets $1 \&$ Template=/Cont entManagement/ContentDisplay.cfm\&ContentID=48112

Bronfenbrenner, U. (1977, July). Toward An Experimental Ecology of Human Development. American Psychologist, 513-531. Retrieved from http://pdfcast.org/pdf/toward-an-experimental-ecology-of-human-development

Burgess, C. (2000). Internal And External Stress Factors Associated With The Identity Development Of Transgendered Youth. Journal Of Gay \& Lesbian Social Services, 10(3-4), 35-47. http://dx.doi.org/10.1300/JD4 Iv10n03 03

Caitlin, R. (Fall/Winter, 2009). Helping Families Support Their Lesbian, Gay, Bisexual, and Transgender (LGBT) Children. Retrieved 08/31/2013, from http://nccc.georgetown.edu/documents/LGBT_Brief.pdf

Catania, J. A., \& Dolcini, M. M. (2012). A Social-Ecological Perspective on Vulnerable Youth: Toward An Understanding Of Sexual Development Among Urban African American Adolescents. Research In Human Development, 9(1), 1-8. http://dx.doi.org/10.1080/15427609.2012.654428 
Center for Disease Control Fact Sheet: PrEP: A New Tool for HIV Prevention. (2012). Retrieved from http://www.cdc.gov/nchhstp/newsroom/docs/2012/PrEPFactSheet-080912-508.pdf

Centers for Disease Control and Prevention. (2011). HIV infection among transgender people. Retrieved from http://www.cdc.gov/hiv/transgender/pdf/transgender.pdf Center of Excellence for Transgender HIV Prevention. (2009). Recommendations for inclusive data collection of trans people in HIV prevention care and service. Retrieved from http://transhealth.ucsf.edu/pdf/data-recommendation.pdf

Conron, K. J., Scott, G., Stowell, G. S., \& Landers, S. J. (2012). Transgender health in Massachusetts: Result from a household probability sample of adults. American Journal of Public Health, 1021, 118-122.

http://dx.doi.org/10.2105/AJPH.2011.300315

Diaz, R. M., Ayala, G., Bein, E., Henne, J., \& Marin, B. V. (2001, June). The impact of homophobia, poverty, and racism on the mental health of gay and bisexual Latino men: Findings from 3 US cities. American Journal Of Public Health, 91(6), 927932.

Division of HIV/AIDS Prevention. (2011). HIV among transgender people. Retrieved from Retrieved from http://www.cdc.gov/hiv/transgender/pdf/transgender.pdf

Edward, K., \& Welch, T. (2011, October). The extension of Colaizzi's method of phenomenological enquiry. Contemporary Nurse, 39(2), 163-171.

Galea, J. T., Kinsler, J. J., Salazar, X., Lee, S., Giron, M., Sayles, J. N., ... Cunningham, W. E. (2011). Acceptability of pre-exposure prophylaxis as an HIV prevention strategy: Barriers and facilitators to pre-exposure prophylaxis uptake among at- 
risk Peruvian populations. International Journal of STD \& AIDS, 22, 256-262. http://dx.doi.org/10.1258/ijsa.2009.009255

Galindo, G. R. (2013, February). A loss of moral experience: Understanding HIV-related stigma in the New York City house and ball community. American Journal of Public Health, 103(2), 293-299. http://dx.doi.org/10.2105/AJPH.2012.300916

Garofalo, R., Deleon, J., Osmer, E., Doll, M., \& Harper, G. W. (2006). Overlooked, misunderstood and at-risk: Exploring the lives and HIV risk of ethnic minority male-to-female transgender youth. Journal of Adolescent Health, 38, 230-236. http://dx.doi.org/10.1016/j.jadohealth.2005.03.023

Garofalo, R., Osmer, E., Sullivan, C., Doll, M., \& Harper, G. (2006). Environment, psychosocial, and individual correlates of HIV risk in ethnic minority male-tofemale transgender youth. Journal of HIV/AIDS Prevention In Children \& Youth, 7(2), 89-104. http://dx.doi.org/10.1300/J499v07n02_06

Gates, G. J. (2011). How many people are lesbian, gay, bisexual, and transgender? Retrieved from http://williamsinstitute.law.ucla.edu/wp-content/uploads/GatesHow-Many-People-LGBT-Apr-2011.pdf

Grant, R. M., Lama, J. R., Anderson, P. L., McMahan, V., Liu, A., Vargas, L., ... Glidden, D. V. (2010, December, 30). Preexposure Chemophylasix for HIV prevention in men who have sex with men. The New England Journal of Medicine, 363(27), 2587-2599. http://dx.doi.org/10.1056/NEJMoal011205

Grossman, A. H., \& D'augelli, A. R. (2006). Transgender Youth. Journal Of Homosexuality, 51(1), 111-128. http://dx.doi.org/10.1300/J082v5ln0106 
Holloway, I., \& Wheeler, S. (2010). Qualitative research in nursing and healthcare (3rd ed.). West Sussex: Wiley-Blackwell.

Hunt, J., \& Moodie-Mills, A. (2012). The unfair criminalization of gay and transgender youth: An overview of the experiences of LGBT youth in the juvenile system. Retrieved from http://www.americanprogress.org/issues/lgbt/report/2012/06/29/1 1730/the-unfaircriminalization-of-gay-and-transgender-youth/

Keatley, J., \& Bockting, W. (2008). What are male-to-female transgender person's (MtF) HIV prevention needs? Retrieved from http://caps.ucsf.edu/uploads/pubs/FS/pdf/revMtFFS.pdf

Kosciw, J. G., Greytalk, E. A., \& Diaz, E. M. (2009, 7 May). Who, What, Where, And Why: Demographic And Ecological Factors Contributing To Hostile School Climate For Lesbian, Gay, Bisexual, And Transgender Youth. Journal Of Youth Adolescence, 38, 976-988. http://dx.doi.org/10.1007/s10964-009-9412-1

Logie, C. H., James, L., Tharao, W., \& Loutfy, M. R. (2011). HIV, Gender, Race, Sexual Orientation, And Sex Work: A Qualitative Study Of Intersectional Stigma Experienced By HIV-Positive Women In Ontario, Canada. PLoS Medicine, 8(11), e1001124. http://dx.doi.org/10.1371/journal.pmed.1001124

Merleau-Ponty, M. (1945). Phenomenology of perception. New York, NY: Routledge \& Kegan Paul. 
Polit, D. F., \& Beck, C. T. (2010). Generalization in quantitative and qualitative research: Myths and strategies. International Journal of Nursing Studies, 47, $1451-1458$. http://dx.doi.org/10.1016/j.ijnurtu.2010.06.004

Polit, D. F., \& Beck, C. T. (2012). Nursing research: Generating and assessing evidence for nursing practice (9th ed.). London: Wolter Kluwer/ Lippincott Williams \& Wilkins.

Ream, G. L., Barnhart, K. F., \& Lotz, K. V. (2012). Decision Processes About Condom Use Among Shelter-Homeless LGBT Youth In Manhattan. AIDS Research And Treatment, 2012(ID 659853).

Sadala, M. L.A., \& Adorno, R. DE C. F. (2002). Phenomenology as a method to investigate the experience lived: A perspective from Husserl and Merleau Ponty's thought. Journal of Advanced Nursing, 37(3), 282-293.

Stevens, R., Bernadini, S., \& Jemmott, J. B. (2013, 26 July). Social environment and sexual risk-taking among gay and transgender African American youth. Culture, Health \& Sexuality: An International Journal for Research, Intervention, and Care. http://dx.doi.org/10.1080/13691058.2013.809608

Stieglitz, K. A. (2010, May/June). Development, Risk, And Resilience Of Transgender Youth. Journal Of The Association Of Nurses IN AIDS Care, 2l(3), 192-206. http://dx.doi.org/10.1016/j.jana.2009.08004

Vargas, K., Dew, B., Marshall, M., Graybill, E., Singh, A., Meyers, J., \& Birckbichler, L. (2008). Bullying In Schools Towards Sexual Minority Youth. Journal Of School Violence, 7(2), 59-86. http://dx.doi.org/10.1300/J202v07n02_05 


\author{
Manuscript \# 1 \\ Transgender: A Concept Analysis \\ Gloria Nwagwu MSN, FNP-BC, RN \\ Hahn School of Nursing and Health Sciences \\ University of San Diego
}

\begin{abstract}
Transgender as a state of mind is poorly understood by the public and among health care providers. Individuals experiencing discomfort with their birth sex and gender identity often experience discrimination and victimization. The process of transitioning to the opposite gender may be associated with stigmatization related to deviation from the culturally accepted dichotomy of male and female gender. The method described by Walker and Avant (2011) was utilized to develop a concept analysis of transgender, describing its attributes, antecedents, consequences, and empirical referents as well as cases that further clarify the concept. The outcome of the analysis provides clarity on the concept of transgender to facilitate research on health and psychosocial challenges confronting these sexual minority individuals. The practice implications for health care providers include increased knowledge of the concept of transgender to enhance health promotion and disease prevention interventions.
\end{abstract}


Key words: Transgender, gender dysphoria, transsexual, transvestite, Sexual reassignment surgery 


\section{Introduction}

Transgender refers to a state of mind in which an individual experiences dissonance between birth sex and gender identity. Individuals that experience incongruity between birth sex (anatomical genitalia) and gender identity (inner self-perception as female or male) are grouped under an umbrella term known as transgender. Although the transgendered individual as a group is currently more visible in the society, the concept of transgenderism remains poorly understood. Transgender individuals do not conform to the culturally accepted gender dichotomy of male and female. The transgendered individuals self-identify in various subgroups including female, male, male-to-female $(\mathrm{MtF})$ and female-to-male (FtM), transsexuals, transwomen, Transmen, transvestites or cross dressers, bigenders, and drag queens and drag kings (Centers for Disease Control and Prevention [CDC], 2011).

The stigma and victimization associated with transgenderism, in conjunction with a lack of valid tools to collect sexual and gender identity information, impede accurate estimates of the transgender population. Currently available data collection tools are limited to the culturally acceptable dichotomy of male and female genders to the exclusion of transgendered individuals. Nevertheless, valid population estimation is essential for appropriate resource distribution, disease prevention, and management. Based on incomplete data extracted from various lesbian, gay, bisexual, and transgender (LGBT) surveys, the transgender population constitutes about $0.3 \%$ of the population in United States (Gates, 2011 ). 
Current gaps in knowledge do not allow for full comprehension of the complexity of health issues for transgender individuals. Transgender individuals experience a number of factors that influence their health. For example, the process of transitioning to the opposite gender may have negative consequences for transgendered individuals, such as rejection by family and peers, discrimination, isolation, stigmatization, and victimization (Bockting, Miner, Swinburne, Hamilton, \& Coleman, 2013; Division of HIV/AIDS Prevention [DHAP], 2011; Conron, Scott, Stowell, \& Landers, 2012). The cost of required hormones, steroids, and physical surgical alterations for transitioning to the opposite gender often constitute financial burdens as they are frequently not covered by medical insurance (Alegria, 2011). For some transgender individuals, the perceived urgency of transitioning to the opposite gender is such a priority that they are willing to involve themselves in HIV risk behaviors to finance the medical costs. Members of the transgender population have been linked to a high rate of new HIV infection (DHAP, 2011). The aim of this concept analysis was to identify the different uses of the concept of transgenderism and clarify the concept to facilitate research on this sexual minority group. The eight-step method of selecting a concept; determining the aims or purposes of the analysis; identifying all uses of the concept; determining the defining attributes of the uses of the concept; identifying a model case; identifying borderline, related, contrary, invented and illegitimate cases; identifying antecedents and consequences and defining empirical references was utilized to accomplished this concept analysis (Walker \&Avant, 2011).

\section{Definition and Concept Uses}


In order to formulate a robust understanding of the concept of transgender it is necessary to explore the varied uses of the term from all available sources (Walker \& Avant, 2011). The use of transgender was explored using various data sources including the Oxford Dictionary, Mariam Webster Dictionary, CINAHL, PUBMED, LGBT life, and PsychINFO. According a search of the Merriam Webster's Online Dictionary (Transgender, n. d.), "Transgender" is an adjective that describes an individual who identifies as or expresses a gender identity opposite the birth sex or gender.

Although transgender is an all-embracing term for individuals who express incongruence with their birth sex and a strong affinity to self-identify as the opposite gender, there are varied self-representations among this sexual minority group. The commonality among subgroup members is embedded in the dissociation from their birth sex and strong affinity to identify as a member of the opposite sex. The level of discomfort with birth sex and desire to identify as the opposite gender often determines the extent of commitments to alteration of the physical body (Alegria, 2011). Transgender refers to people whose self-perceived gender identity fails to align with the social and culturally accepted binary gender of male and female (DHAP, 2011); or people whose "psychological self" defers from the "physical sex" (Gender Equity Resources Center, n.d.).

Historically, the term currently recognized as transgender can be traced to differently constructed words in various cultures and regions of the world. Through story telling and legends, individuals of "third gender" or "third sex" role provide references to gender variant people through the use of such terms as bakla (Tagalog), shamakhami (Bengali), waria (Javanese), paksu mudang (Korean), and mahu (Hawaiian) (Park \& 
Manzon-Santos, 2000). However, the first recognized use of transgender to describe persons that "thought, felt, and acted," like a member the gender opposite to their birth sex and noted to be different from transvestites or cross dressers (who dress in opposite gender clothing for entertainment purposes) was found in the work of Dr. Magnus Hirschfeld in 1910 (Bullough, 2000).

As a subgroup of transgender individuals, "transsexual" is used to describe individuals who experience dissociation between their self-identified sex and birth sex (Gender Equity Resources Center, n.d.). Some transsexual individuals seek and receive hormonal therapy and/or sexual reassignment surgeries to better align their physical sex with their gender identity to conform to cultural norms and so ameliorate gender discomfort. The transsexual woman, or male to female (MtF) transgender, was exemplified in 1952 when Christine Jorgensen became the first person to transition from biological male (natal male) to female after sexual reassignment surgery (SRS) (Currah, 2008). Transsexual people may be called by different terms, such as Kathoey in Thailand and hijras in India, to designate individuals following SRS.

Transsexual individuals are frequently in a fluid state moving between the subgroups of gender self-identification during the transition process. Some pursue and complete the process with hormones and/or SRS as in the case of self-identified male-tofemale $(\mathrm{MtF})$ and female to male $(\mathrm{FtM})$ transgender individuals. There are also those "genderqueer" transgender individuals that choose to remain in a transition state and selfidentify as male, female, MtF, FtM, bi-gender, or non-identifiable gender without physical alterations (Veale, Clarke, \& Lomax, 2008). Table 1 provides a partial list of terms related to subgroups of transgender individuals. 
As an umbrella term, transgender is used positively by community organizations and advocates educating both transgender individuals and the public on issues affecting this sexual minority (Center of Excellence for Transgender HIV Prevention, 2009). The media may be utilized by individuals to embrace awareness and recognition of the transgender population, as in the publication of news about a transgender female running for home coming queen (Flores, 2013). Conversely, the media is also utilized to promote rejection, insensitivity, and discriminatory propaganda against transgender individuals, as in the report by the education editor of the Daily Caller denouncing the right of transgender individuals to use bathrooms designated for members of their self-identified gender (Brinker, 2013).

Empirical uses of transgender are within the framework of psychosocial and health related issues. Transgender is used in research studies that seek to define the varied subgroups of transgenderism (Alegria, 2011; Bullough, 2000; Conron et al., 2012). The transgender population is described as a gender minority group whose biological sex is at odds with culturally acceptable dichotomous gender designations. Subgroups of the transgender population, the male to female transgender individuals, may engage in HIV risk behaviors and are the greatest contributors to new HIV infections (DHAP, 2011). The transgender population is discussed within the context of the impact of discrimination, stigma, injection drug practices, and mental health disorders affecting the population and strategies for health promotion and disease prevention (DHAP, 2011). The common phenomena associated with the transgender population in areas of research, education, and practice are related to consequences of transgenderism and HIV prevention and health care delivery for transgender individuals (Alegria, 2011; Lawrence, 
2010; Siebler, 2012). Transgender is also used to describe vulnerable, rejected, and beleaguered individuals with a history of depression and low self esteem that experience violence, physical and sexual abuse (DHAP, 2011).

\section{Defining Attributes}

Attributes are the re-occurring themes found in the uses of the concept that enable full comprehension and interpretation of the concept of interest (Walker \& Avant, 2011). The main defining attributes of transgenderism, based on the literature review, are incongruity between sexual and gender identity, gender dysphoria, and non-conforming gender expression. According to the Oxford Dictionary (Incongruence, 2013), incongruence is described as a mismatch or non-alignment. Gender dysphoria refers to the experienced discomfort associated with perceived incongruity between birth sex and gender identity (IOM, 2011). The experience of gender discomfort is described almost always at the time of self discovery of incongruity of physical sex assigned at birth with perceived self identified gender that it can also be viewed $a$ as an antecedents of the concept of transgender. So for the purpose of this analysis, gender dysphoria will be explored both as an attribute and as an antecedent. Non-conforming gender expression refers to non-adherence to behaviors in keeping with cultural norms of male and female roles.

\section{Incongruity}

The hallmark of transgenderism is incongruity between assigned sex at birth, based on anatomical genitalia, and the self-identified gender. Generally, sex that denotes male, female or intersex assigned at birth is culturally accepted to be in congruence with dichotomous gender roles. Hence, individuals are expected to grow up as representative 
of the gender aligned with their assigned birth sex. In transgender individuals, there is a feeling of being born in a "wrong body" or incongruence of sex with gender (Alegria, 2011; DHAP, 2011; IOM, 2011). As discussed earlier, various subgroups of transgender individuals exhibit non-conformity to the socially constructed binary system of male and female.

\section{Gender Dysphoria}

Gender dysphoria (GD) refers to the discomfort associated with incongruence between one's biological sex and one's perceived gender identity as male or female (Kuyper \& Wijsen, 2013). The onset of gender dysphoria is unclear as available data is based on retrospective reports from parents, adolescents, and adult transgender individuals seeking medical attention.

Gender dysphoria was considered a symptom of gender identity disorder, a mental disorder diagnosis, in the Diagnostic and Statistical Manual of Mental Disorders, fourth edition (DMS IV) (American Psychiatric Association [APA], 2000. In the current edition of DSM 5, gender dysphoria is recognized as a stand-alone diagnosis. This change from DSM IV, allows for consideration of the various types of gender incongruence as well as different levels of discomfort (dysphoria) among individuals experiencing gender mismatch identity. There are now available specific criteria for diagnosis of gender dysphoria for children, adolescents, or adults (APA, 2013).

The three main aspects of gender dysphoria include gender identity, affinity for identifying as a member of the opposite gender, and discomfort with biological sex (Kuyper \& Wijsen, 2013).

\section{Non-Conforming Gender Expression}


The transgender population experiences strong affinity to cross-gender expression transgressing the dominant assigned gender expression. Most transgender individuals experiment with cross-dressing and opposite gender mannerisms prior to gender transition. According to Kuyper and Wijsen (2013), gender expression was exhibited as wishing to be and acting as a member of the opposite sex as recounted by parents of some gender variant children. The characteristics of non-conforming gender expression are self-expression as male or female in behavior, manner, and or dress (Walch, Ngamake, Francisco, Stitt, \& Shingler, 2012).

\section{Antecedents}

Antecedents are "those events or incidents that must occur or be in place prior to the occurrence of the concept" (Walker \& Avant, 2011, p. 167). While the existence of transgenderism has been linked to ancient high gods or priests, there is a surfeit of documentations of discomfort experienced by transgender individuals following self recognition of the misalignment of birth sex with self identified gender (DHAP, 2011; Kuyper \& Wijsen, 2013). An antecedent for all transgender individuals is birth into a heterosexual binary gender-focused society that aligns anatomical genitalia with expected gender role. Although there is no study supporting this, anecdotal evidence points to the idea that some gender variant individuals contend that the societal dichotomous environment sets the stage for the transgender individual's perceived state of sex and gender mismatch and subsequent discomfort at being different from the norm. The development of self-awareness of discrepancy between anatomical sex and inner feeling as a member of the opposite sex as well as affinity to express as the opposite gender is an 
important antecedence as it often marks the beginning of dysphoria and subsequent engagement in the transition process for many transgender individuals.

\section{Consequences}

Consequences are those incidents or outcomes occurring because of the concept.

Often gender expression that is non-conforming to culturally acceptable practice may be a source of discrimination, isolation, and stigma that result from transphobia in the heterosexual population. Transphobia is described as individual, societal, or institutionalized discrimination against gender non-conforming individuals (Nemoto, Bodeker, \& Iwamoto, 2011; Sugano, Nemoto, \& Operario, 2006). Transgender individuals experience physical, societal, and psychological consequences as they begin to transition to the opposite gender or "come out."

The discomfort, confusion, and internalized stress stemming from incongruity between assigned birth sex and self-identified gender are factors contributing to possible self-abusive behaviors. The engagement in injection hormones for physical transformation to the opposite gender or sexual reassignment surgery is often related to the level of discomfort and commitment to the process of transition (Conron et al., 2012). Furthermore, study indicates small subgroups of male-to-female transgender individuals that engage in sex work at high risk for HIV infection and sexually transmitted infections (DHAP, 2011).

Transgenderism has been associated with familial and peer rejection, isolation, and discrimination, often leading to low education levels, homelessness, and unemployment (DHAP, 2011; Garofalo, Deleon, Osmer, Doll, \& Harper, 2006; Grossman \& D'augelli, 2006). Although transgender individuals frequently find support 
within the trans-community, there is the potential for the loss of relationships with primary family and peers because of life as a gender variant individual. Experiences of transphobia, violence, and stigma associated with transgenderism, in conjunction with gender dysphoria, constitute risk factors for mental illness and suicide, especially among transgender youth (Clements-Nolle, Marx, \& Katz, 2006; Garofalo et al., 2006;

Grossman \& D'augelli, 2006). The financial hardships associated with the cost of hormonal injections and SRS procedures and lack of trust in health care providers, as well as perceived provider discrimination, are some of the barriers to healthcare for the transgender population (Alegria, 2011; Clements-Nolle et al., 2006). However, it must be noted that some transgender individuals report self-fulfillment following disclosure and embrace the transition process to live as their true selves (Alegria, 2011).

\section{Empirical Referents}

Empirical referents are classes or categories of actual phenomena that by their existence or presence demonstrate the occurrence of the concept itself (Walker \& Avant, 2011). The culturally accepted dichotomous gender system of male and female inhibits data collection on issues affecting the transgender population as they may be compelled to identify as male or female or, in many cases, decline to participate. Further complicating empirical referents is the fact that transgender individuals are a hidden and difficult to reach population that shies away from disclosure for fear of discrimination, isolation, stigma, and violence. Hence, the only real empirical referent is self-disclosure, which is not particularly valid due to the various subgroups of transgenderism noted earlier, making classification of demographic data difficult. 
To capture data on the transgender population, a two-question system of extricating sex from gender was recommended by the Center for Excellence for Transgender HIV Prevention at the University of California, San Francisco (Sausa, Sevelius, Keatley, Iniguez, \& Reyes, 2009). The two-question system focuses on gender identification information collection allowing for an all-inclusive "trans" subgroup making it easier for transgender individuals to check a box applicable to their identity. The first question asks individuals to select all that applies concerning their sex or gender with boxes representing eight possible answers ranging from "male" to "decline to state"(see Table 3). The second question is directed at assigned sex at birth with four answers ranging from "male" to "decline to state." This data collection approach allows for acknowledgement of assigned sex at birth and also addresses self-identified gender.

\section{Cases}

The next step in concept analysis using Walker and Avant's strategy is the use of cases to illustrate all the essential elements of transgenderism as presented in a model case. Absence of some or all-key attributes are further demonstrated through use of other cases (2011).

\section{Model Case}

A model case is an example of the use of the concept that demonstrates all the defining attributes of the concept (Walker\& Avant, 2011). James, a 28 year-old biological male, was the star quarterback in high school. He was voted "best looking" guy and graduated valedictorian of his high school class. However, beneath his seemingly masculine exterior, he was experiencing personal upheaval. James was born a biological male, but since early childhood has felt an indefinable friction with his sexuality. This 
gender discomfort would continue into adolescence. James hid these feelings from the world for fear of rejection, discrimination, and isolation. To express his innate femininity, at home he would dress as female, to every one's disapproval.

In high school, James was the quintessential teenage boy because he overcompensated to suppress his true feelings. James dated girls and, discretely, boys. In college, James found freedom from the watchful eyes of his parents and began to openly cross-dress as a female. As he became more comfortable with himself as a female, he proceeded to more permanent female physical feature with the use of injectable hormones. As his parents and many of his friends learned about James's transition to female gender, he was consequently rejected and disowned. Finally, in his late 20s, James underwent sexual reassignment surgery and now lives as Janette, following a legal name change.

This case exemplifies the critical attributes of a male to female transgender individual, who was assigned male based on his anatomical sex at birth. At an early age, he acknowledged misalignment of birth sex and self-identification as female and began transitioning to female with the use of injection hormones as he experienced more discomfort (dysphoria), with ensuing rejection and discrimination from peers and family. Finally, James completed the transition process through sexual reassignment surgery and a legal name change as a female (Janette).

\section{Borderline Case}

A borderline case is an example or instance that contains most of the defining attributes of the concept being examined but not all of them (Walker \& Avant, 2011). A borderline case is presented below: 
Justin was a 34-year-old computer analyst, first son of a middle class Roman Catholic family in New Mexico. Justin always wanted to dress in girls' clothing and shared with his mother that he had always felt like a girl. His parents thought Justin's feelings were a phase of adolescence that would fade away. In high school, to everyone's surprise, he auditioned for the cheerleading team making him an object of ridicule. That marked the beginning of Justin's experiences of psychological and physical abuse from classmates and his parents, who threw him out of their home. Living on the street and unable to continue with school, he dropped out and made a living doing odd jobs as a cross-dresser and occasionally engaged in sex- work. He finally joined a communitybased transgender support organization, got a steady job, and returned to school.

However, Justin loves the freedom to move between male and female life so is not taking any injectable hormones or contemplating sexual reassignment surgery. In this borderline case, only some of the attributes of a module case are present. Justin has no intention of engaging in feminizing hormone therapy or sexual reassignment surgery.

\section{Contrary Case}

A contrary case is clearly not a representation of the concept under study (Walker \& Avant, 2011). A contrary case for transgenderism is presented below:

A 43-year-old second generation African American, Austin was born male. He lived at home with his parents and two sisters until he went away to Tufts University in Boston. He graduated and got a job as a mechanical engineer with the city of Los Angeles. Austin is married to his high school girl friend, and they have two children. He has never expressed or had any conflict with his life as a male.

\section{Implications for Research and Practice}


Despite its existence since before the nineteenth century, exploration of the concept of transgenderism has revealed there is still a lack of lucidity regarding the concept. Transgenderism is a noun that describes the incongruity between biological sex and self identified gender experienced by some individuals. While this concept analysis uncovered the attributes and consequences, there is a gap in research explicating the antecedents of the concept of transgender. There is also opportunity for continued research to allow for in-depth understanding of social and psychological consequences of transgenderism so as to plan individualized health promotion and disease prevention care for the gender variant population.

\section{Conclusion}

The concept of transgender was chosen for analysis due to the poor clarity of the concept among the general public and health care providers. Although it is an ancient word used in different cultures and languages to describe individuals who do not conform to the culturally accepted binary sex and gender of female and male, the concept is still not fully understood. There is a paucity of literature concerning its antecedents. The consequences analyzed reveal the physical, social, and psychological burden of transgenderism for the individual. There is gap in research for solutions to address discrimination and minimize stigma, transphobia, depression, and suicide attempts. Rejection and discrimination by advanced practice providers may be a hindrance to access to much-needed healthcare for the transgender population

There is lack of accurate demographic data collection at state and national levels related to sexual minority populations. This may account for the use of 'selfidentification' as a transgender individual as an inclusive criterion for selection of 
participants for research among sexual minority population, even if it is the least reliable process of population identification. Future research based on the two-system questions instrument focusing separately on sex and gender would facilitate accurate data collection related to this hard to reach population and enhance population specific health needs.

Table 1. Definitions of Transgender-Associated Terminology

Birth sex Assigned designation as male or female at birth based on genetic, anatomical, hormonal, and physical characteristics (Institute of Medicine [IOM], 2011)

Gender identity Personal sense of being a man, woman, both, or neither (Alegria, 2011; IOM, 2011)

Gender Discomfort with incongruence between assigned birth sex and self dysphoria identified gender (IOM, 2011).

Gender identity Characterized by: (a) Strong and persistent cross-gender disorder identification; (b) Discomfort with incongruence between birth sex and self identified gender (American Psychiatric Association, 2000; Shechner, 2010)

Transgender An umbrella term describing individuals that experience incongruence with biological sex and self identified gender (IOM, 2011)

Transsexual Individuals that experience misalignment of self-identified sex and birth sex (Gender Equity Resources Center, n.d.)

Transvestite Individuals that dress in opposite gender clothing and have no desire 
for physical or sex change

MtF An individual born male that self- identifies as female. May indulge in hormone treatment or SRS or both to enhance transition process.

FtM An individual born female that self-identifies as male. May indulge in hormone treatment or SRS or both to enhance transition process. 
Table 2. Example of the Two-Question System and Response Options

1. What is your sex or gender? (Check $\underline{A L L}$ that apply)

1) $\rceil$ Male

2) $\mid$ Female

3) Transgender Male/Transman

4) $\mid$ Transgender Female/Transwoman

5) $\backslash$ Genderqueer

6) I! Additional Sex or Gender: Please specify:

7) Unknown or Question Not Asked

8) Decline to State

2. What sex were you assigned at birth? (Check $\underline{\mathbf{O N E})}$

1) ! Male

2) $\mid$ Female

3) 1] Unknown or Question Not Asked

4) 17 Decline to state

Center of Excellence for Transgender HIV prevention (2009).

\section{References}

Alegria, C. A. (2011). Transgender identity and health care: Implications for psychosocial and physical evaluation. Journal of the American Academy of Nurse Practitioners, 23(4), 175-182. http://dx.doi.org/10.1111/j.1745-

7599.2010.00595.x 
American Psychiatric Association. (2000). Diagnostic and statistical manual of mental disorders. Retrieved from http://www.psychiatric.org/dsm4

American Psychiatric Association (2013). Gender Dysphoria. Retrieved from http://www.dsm5.org/Documents/Gender\%20Dysphoria\%20Fact\%20Sheet.pdf

Bockting, W. O., Miner, M. H., Swinburne, R. E., Hamilton, A., \& Coleman, E. (2013). Stigma, mental health, and resilience in an online sample of the US transgender population. American Journal of Public Health, 103(5), 943-951. http://dx.doi.org/10.2105/AJPH.2013.301241

Brinker, L. (2013, September 17). Re: Daily Caller: Equal treatment for transgender people is "special treatment" [Web log comment]. Retrieved from http://mediamatters.org/blog/2013/09/17/daily-caller-equal-treatment-fortransgender-pe/195919

Bullough, V. L. (2000). Transgenderism and the concept of gender. International Journal of Transgenderism, 4(3), 1-12.

Center of Excellence for Transgender HIV Prevention. (2009). Recommendations for inclusive data collection of Trans people in HIV prevention care and service. Retrieved from http://transhealth.ucsf.edu/pdf/data-recommendation.pdf Centers for Disease Control and Prevention, (2011). HIV infection among transgender people. Retrieved from http://www.cdc.gov/hiv/transgender/pdf/transgender.pdf Clements-Nolle, K., Marx, R., \& Katz, M. (2006). Attempted suicide among transgender persons. Journal of Homosexuality, 51(3), 53-69. http://dx.doi.org/10.1300/J082v51 n03 04 
Conron, K. J., Scott, G., Stowell, G. S., \& Landers, S. J. (2012). Transgender health in Massachusetts: Result from a household probability sample of adults. American Journal of Public Health, 102(1), 118-122. http://dx.doi.org/10.2105/AJPH.2011.300315

Currah, P. (2008). Stepping back, looking outward: Situating transgender activism and transgender studies--Kris Hayashi, Matt Richardson, and Susan Stryker frame the movement. Sexuality Research \& Social Policy, 5(1), 93-105. Retrieved from http://www.deanspade.net/wp-content/uploads/2010/08/roundtable.pdf

Division of HIV/AIDS Prevention. (2011). HIV among transgender people. Retrieved from http://www.cdc.gov/hiv/transgender/pdf/transgender.pdf

Flores, A. (2013, September 19). In the running, as herself. Los Angeles Times, pp. AAI, AA4.

Garofalo, R., Deleon, J., Osmer, E., Doll, M., \& Harper, G. (2006). Overlooked, misunderstood and at-risk: Exploring the lives and HIV risk of ethnic minority male-to-female transgender youth. Journal of Adolescent Health, 38(3), 230-236. http://dx.doi.org/10.1016/j.jadohealth.2005.03.023

Gates, G. J. (2011). How many people are lesbian, gay, bisexual, and transgender? Retrieved from http://williamsinstitute.law.ucla.edu/wp-content/uploads/GatesHow-Many-People-LGBT-Apr-2011.pdf

Gender Equity Resources Center. (n. d.). Definition of terms. Retrieved from http://geneq.berkeley.edu/lgbt_resources_definiton_of_terms

Grossman, A. H., \& D'augelli, A. R. (2006). Transgender youth. Journal of Homosexuality, 5l(1), 111-128. http://dx.doi.org/10.1300/J082v5ln0106 
Institute of Medicine. (2011). The health of lesbian, gay, bisexual, and transgender people: Building a foundation for better understanding. Washington, DC: National Academies Press.

Kuyper, L., \& Wijsen, C. (2013). Gender identities and gender dysphoria in the Netherlands. Archives of Sexual Behavior, 42(5) N.A. http://dx.doi.org/10.1007/s 10508-013-0140-y

Lawrence, A. A. (2010). Sexual orientation versus age of onset as bases for typologies (subtypes) for gender identity disorder in adolescents and adults. Archives of Sexual Behaviors, 39(2), 514-545. http://dx.doi.org/10.1007/s10508-009-9594-3

Nemoto, T., Bodeker, B., \& Iwamoto, M. (2011). Social support, exposure to violence and transphobia, and correlates of depression among male-to-female transgender women with a history of sex work. American Journal of Public Health, 10I(10), 1980-1988. http://dx.doi.org/10.2105/AJPH.2010.197285

Park, P., \& Manzon-Santos, J. (2000). Issues of transgendered Asian Americans and Pacific Islanders. Retrieved from http://www.apiwellness.org/article $\mathrm{tg}$ issues.html

Sausa, L. A., Sevelius, J., Keatley, J., Iniguez, J. R., \& Reyes, M. (2009). Policy recommendation for inclusive data collection of trans people in HIV prevention, care and services. Retrieved from http://www.transhealth.ucsf.edu/tcoe?page=libdata-collection

Shechner, T. (2010). Gender identity disorder: A literature review from a developmental perspective. Israel Journal of Psychiatry Related Science, 47(2), 132-138. 
Retrieved from http://doctorsonly.co.il/wpcontent/uploads/2011/12/2010_2_7.pdf

Siebler, K. (2012). Transgender transitions: Sex/gender binaries in the digital ages. Journal of Gay \& Lesbian Mental Health, 16(1), 74-99. http://dx.doi.org/10.1080/19359705.2012.632751

Sugano, E., Nemoto, T., \& Operario, D. (2006). The impact of exposure to transphobia on HIV risks behavior in a sample of transgendered women of color in San Francisco. AIDS and Behavior, 10(2), 217-225. http://dx.doi.org/10.1007/s 10461005-9040-z

Transgender. (n.d.). In Merriam Webster's online dictionary ( $11^{\text {th }}$ ed.). Retrieved from http://www.merriam-webster.com/dictionary/transgender/

Transgenderism. (2013.) The Oxford Dictionaries. Retrieved from http://ox forddictionaries.com/definition/english/transgenderism

Veale, J. F., Clarke, D. E., \& Lomax, T. C. (2008). Sexuality of male-to-female transsexuals. Archives of Sexual Behavior, 37(4), 586-597. http://dx.doi.org/10.1007/s10508-007-9306-9

Walch, S. E., Ngamake, S. T., Francisco, J., Stitt, R. L., \& Shingler, K. A. (2012). The Attitudes Toward Transgendered Individuals Scale: Psychometric properties. Archives of Sexual Behavior, 41 (5), 1283-1291. http://dx.doi.org/10.1007/s10508-012-9995-6

Walker, L. O., \& Avant, K. C. (2011). Strategies for theory construction in nursing (5th ed.). Upper Saddle River, NJ: Prentice Hall. 
Manuscript \# 2

A Phenomenological Study Of Acceptability Of Pre-Exposure Prophylaxis Within The Lived Experiences Of HIV Negative Male-To-Female Transgender Young Adults

\author{
Gloria Nwagwu MSN, FNP-BC, RN \\ Hahn School of Nursing and Health Sciences \\ University of San Diego
}

\begin{abstract}
Purpose: The purpose of this qualitative phenomenological study was to describe the acceptability of pre-exposure prophylaxis therapy (PrEP) within the context of lived experiences in HIV negative male-to-female transgender (MtF-TG) young adults.
\end{abstract}

Background: MtF-TG young adults often experience discrimination from family members, peers, and the larger community. They also have a high rate of homelessness and may engage in-high risk sexual behaviors, including sex work, as a means of financial support. These behaviors render them vulnerable to HIV infection and other sexually transmitted infections. The use of Preexposure exposure prophylaxis therapy (PrEP) among men that have sex with men (MSM) and MtF-TG individuals decreases HIV infection. When used in conjunction with condoms, PrEP protects against HIV.

Study Design and Methods: This descriptive phenomenological study included $15 \mathrm{MtF}-$ TG young adults who voluntarily responded to open-ended semi-structured interviews. The digitally recorded interview was transcribed verbatim and analyzed using the Colaizzi method to identify major themes related to acceptability of PrEP within the context of lived experiences as transgendered individuals.

Results: There were four cluster themes that described the acceptability of PrEP therapy within the context of the lived experiences of HIV negative MIF-TG young adults. The themes were: attributes of male-to-female transgender, essence of life as MtF-TG; motivators for PrEP acceptability; and barriers to acceptability of PrEP therapy. 
Implications: This was an initial attempt to describe the acceptability of PrEP within the lived experience of MtF-TG young adults. Findings from this study have the potential to inform best practices for PrEP implementation among the high-risk sexually vulnerable MtF-TG population.

Key Words: male-to-female transgender (MtF-TG), phenomenology, transgender, gender dysphoria, transwomen. 


\section{Introduction}

The Male-to-Female Transgender (MtF-TG) population is a subgroup of the Transgender population that has been identified in the United States as being at the highest risk for new human immunodeficiency virus (HIV) infection. Ethnic minority MtF-TG young adults are at higher HIV risk related to life stressors compared to other racial and sexual minorities. In 2010, African American youth, ages 13-24, accounted for $59 \%$ of new HIV infections compared to $20 \%$ among Hispanic/Latino youth and White/Caucasian youth in 46 states and five U.S. dependent areas (Center for Disease Control Vital Signs, 2012). Environmental stressors resulting from isolation, depression, and discrimination during adolescent development a compound the already existing gender dysphoria present among MtF-TG young adults (Garofalo, Osmer, Sullivan, Doll, \& Harper, 2006). Additionally, the social discrimination and stigma that MtF-TG experience is associated with poor mental health, poverty, isolation, low education, injection drug use, unemployment, with high-risk sexual behavior as a sequel to HIV infection (CDC, 2011; Nemoto, Operario, Keatley, \& Villegas, 2004).

Different approaches have been explored and implemented to address the issue of HIV among MtF-TG individuals, including the high impact prevention project implemented by the Center for Disease Control (CDC) and partners to augment existing approaches of education regarding safe sex and HIV testing campaigns (Center for Disease Control Fact Sheets, 2013). Recently, the USFDA approved the use of a combination of tenofovir and emtricitabine (Truvada ${ }^{\circledR}$ ) in July 2012, as a Pre-Exposure Prophylaxis (PrEP) Therapy method for HIV prevention among high-risk population 
groups (CDC, 2012). Truvada has been in use since 2004 for treatment of HIV; however, a new application of its use was introduced following promising results of the investigation for the Pre-Exposure Prophylaxis Initiatives (iPrEX) with 44\% efficacy in HIV prevention among HIV negative men who have sex with men (MSM) and MtF-TG (CDC: Fact Sheet, 2012; Grant et al., 2010). Other studies documented higher efficacies in the range of $63-73 \%$ of HIV prevention in populations of HIV negative MSM and Trans-women when combined with behavioral prevention methods (Grant et al., 2010). Additional studies indicate a potential for a higher rate of HIV prevention with PrEP when enhanced compliance with the medication regimen is present (CDC, 2011).

Based on current knowledge, PrEP is a promising intervention for HIV prevention among high-risk adult population. MtF-TG young adults are a particularly high-risk population that could benefit from PrEP therapy. The purpose of this study was to describe the acceptability of PrEP within the context of the lived experiences of HIV negative MtF-TG persons ages 18-25. It is expected that the results of this study will supplement current HIV prevention methods and augment implementation rollout programs of PrEP among sexually vulnerable and sexual minority population.

\section{Study Design and Methods}

The descriptive phenomenological method was used in this study and was guided by the underpinnings of Merleau Ponty's philosophical views. In Merleau Ponty's work, existentialist phenomenology views the individual as a body living in a preexisting world and having a reciprocate relationship with that world (Sadala \& Adorno, 2002). Descriptive phenomenology uses the process of bracketing requiring the researcher to acknowledge personal bias and prior beliefs to capture the meaning of phenomena. 
Phenomenological research is an iterative process of continual verification of data throughout the process of data collection and analysis, thereby ensuring the rigor of study methodology (Lopez \& Willis, 2004).

Purposive sampling was used to select individuals $18-25$ years of age living in a large city in California who were born male but self-identify as MtF-TG. Individuals could be at varying stages of transition. They needed to communicate in English and self-report a HIV-negative result within the 3 months prior to the study. Female-to Male transgender (FtM-TG), MSM, gay, lesbian, and bisexual individuals did not participate in the study.

Semi-structured interviews were used to collect the study data. Each interview lasted 30-45 minutes and was transcribed verbatim. Fifteen participants were needed to reach data saturation. An Institutional Review Board at the University of San Diego provided institutional oversight for the study.

Colaizzi's seven-steps of data analysis were employed. First, the researcher rereads the transcripts several times to ensure understanding of participants' words. Next, phrases and sentences related to the phenomenon were extracted and meanings were assigned to formulate concepts. Concepts were then merged into specific theme categories. The primary investigator derived specific theme categories. Final concepts were grouped to formulate a comprehensive and completed description of the phenomenon of study. Credibility of the study was maintained through the researcher's exercise of prolonged engagement with the data collection, analysis, and use of the researcher's words as approved by the participants in the final description of the phenomenon of study. Dependability and conformability were ensured as the researcher 
engaged in an iterative process with recorded audio files and transcribed the interviews to avoid interjecting personal bias in the meaning of extracted data. The researcher did not review prior studies before engaging in data analysis to avoid the influence of those studies on the results of the current study.

\section{Results}

Of the 15 participants, 5 were White, 7 were African Americans, 2 were Hispanic, and I was Asian. Participants were 18-25 years of age; 2 lived at home with parents and 13 were either homeless or living in an emergency shelters accommodation. Two participants had some college while the remaining had a high school or less than a high school education. Only one was on parent's medical insurance and the others either had Medical or was in the process of applying for medical insurance under the Affordable Care Act. Fourteen were unemployed. Some of the unemployed occasionally engaged in sex for money to secure basic needs and others received government relief assistance. One participant was employed in a low wage Hollywood studio job.

The analysis resulted in four cluster themes (see Table 1). These four cluster themes described the acceptability of PrEP Therapy within the context of lived experiences of HIV negative MtF-TG young adults and included: (a) attributes of maleto-female transgender (MtF-TG), (b) the essence of life as MtF-TG individuals, (c) motivators for PrEP acceptability; and (d) barriers to acceptability of PrEP Therapy. Each cluster theme is supported by one to three themes.

Table I

Theme Clusters and Themes

\begin{tabular}{ll}
\hline \multicolumn{1}{c}{ Theme Clusters } & \multicolumn{1}{c}{ Themes } \\
\hline Attributes of Male-To-Female & 1. Incongruity \\
Transgender & 2. Discomfort \\
& 3. Moment of Clarity
\end{tabular}


Essence Of Life As MtF-TG

Motivators for Acceptability of

Preexposure Prophylaxis Therapy

Barriers to PrEP Acceptability
1. Discrimination

2. Need for Acceptance By Others As Female

1. Use of PrEP For Self-Protection

2. Fear of HIV

1. Misconception regarding use of Preexposure Prophylaxis therapy

2. Oppositions To Use Of PrEP

3. Lack Of Desire for PrEP

\section{Attributes of Male-To-Female Transgender (MtF-TG)}

This cluster was defined by the acknowledgement of the "feeling" of difference between birth sex and self identified gender. Participants' experience was similar across cases. This cluster includes three themes: incongruity, discomfort, and moment of clarity.

Incongruity. The first concept was incongruity as recognized by each individual at an early age of difference in the birth sex centered on anatomical genitalia and self identified gender. Most participants recalled feeling different and associating with feminine mannerisms and toys at very young age. One participant stated:

There was never a realization for me. It was something that was very natural to me but uhm, my grandmother told me that when I was younger my dad took me to a doctor and because you know, I kept telling them like I'm a girl, I am a girl, you know, I don't remember this at all. I was like probably like 4 years old and the doctor had said like, we lived in Texas at that time and they said they had never seen somebody so young, you know, identify themselves as a woman. And, you know, naturally my dad was afraid for me to transition and so I was kind of forced to suppress those feelings and they went away for a little bit but I always 
knew like in my head like I'm a woman and I would always... whenever I played with other kids like I would always feel like the princess.

Another shared:

My mom was deported to Guatemala. So after when I was 5, I went to go live with my aunt and my aunt reversed everything. She was like, nope, that's not gonna happen here. We're Catholic and you have to be a boy and all that stuff but the thing is it didn't, I couldn't, I mean I stayed a boy for a few years but up to when I was 12 I just couldn't do it anymore because I was so used to it from when I was little, you know, and I felt like I was living somebody else's life. So then, at 12 , no at 11 , I said I was training into a skater, so I started letting my hair grow back out at 11 and it was just you know part of the look. So once my hair was up to my shoulders by when I was 12 , at school, I was back on, I was a girl, and I look like a girl and it has been.

Another said:

You know like, I want to say about like second or third grade. Like I just always knew I was different, like I always knew something about me was different. I always knew like I just stood out and that's -- ever since then, I just always not felt like myself and around like --, my sophomore year of high school that's when I just realized like, there's something different. I have to start and move and pushing myself to a different direction, so that's how it started.

Discomfort. The other issue that MtF-TG young adults experienced was feeling trapped in the wrong body, which caused emotional turmoil, moments of awkwardness, 
discomfort, and reproach in response to self-identified gender expression. A participant mentioned:

Yea the uncomfortableness goes back to way back when I was a kid, $m m h h m m$, you know like playing baseball and stuff and you are in that really male environment and you are pushed towards acting very masculine and it made me feel very uncomfortable and it wasn't comfortable acting in that very hyper aggressive and very hyper boyish way, you know, I kinda wanted to do more feminine things. And you know then I would do something feminine and you know, and somebody would kinda get, "hey your being. don't be that way, you can't be that way you have to be like a boy" and you know it makes you uncomfortable it makes you upset it makes you feel all kinds of weird emotions. Moment of clarity. Some participants discussed periods of questioning and uncertainty prior to gender realization as transgender. However, many MtF-TG young adults described moments of clarity defined as a moment of self-recognition or inner acknowledgement of the gender difference from gender at birth based on anatomical genitalia. A participant said:

Um, well how it usually began like for most people. Like when you're a kid, something doesn't feel necessarily right and you deal with this uncomfortablness for so long that you start to think about what's going on, you know, and uh so you kind of slowly piece it together over the years. I guess the point that I was really able to admit it to myself and really like hard line be like that was about 20,20 and half, oh really ok, that was uh you know um and that's that you are admitting it to yourself. Like you're not telling anyone else like that type of deal. 
Another stated:

Uhm, well, I was like probably like two or three when I was just like -- kind of like -- cause you know I live in a Christian family, so I kind of like in a way pray that once I wake up in the morning that you know I become a girl but then you know I guess I just came to the conclusion of transitioning, uhm, probably when I was 21 . I mean I started since I was 17, started just like wearing makeup and all that and it just gradually like, you know, it gradually became more like feminine and more, you know, and I felt more comfortable and more happy.

In a final example, a participant said:

Uhm. I don't know. I was like around four or five and I knew something was different and I like to play with the girls stuff and then, uhm, when I hit middle school I realized I was gay but then after high school that's when I found out about what transgender was and I was like okay this make sense."

\section{Essence of Life as a Male-To Female Transgendered Individual}

The concept of the essence of life as MtF-TG person was detailed by many of the participants as they shared their experiences with attempting to educate the world at large about their plight.

Discrimination. Most of the participants experienced discrimination at some point in their lives. Many spoke of dropping out of school because of taunting from other students and teachers. For those displaced from home, experiences of physical and verbal abuse related to gender expression continued at foster homes and shelters. The community offered no protection and some spoke of discriminatory experiences at the hands of teachers, pastors, and employers. One participant shared: 
Uhm, at first some people weren't. When I first started working, uhm, some people, they were comfortable with it like they just were friendly and started talking to me but a lot of the crew members were very distant and 1 will be working with them and we not say like one word to each other. So, it was very awkward and I was thinking to myself okay just give them some time just to get used to it because they've never been around a transgender person before. So, just give them some time but then after a while I started getting mad because this is like look you see l'm a normal person, I do my job just as good as you. Like I'm not an alien here why are you still like just so shocked that I can function and do things?

Need for acceptance by others as female. MtF-TG individuals exert great effort to achieve congruence between their inner feelings as a woman and a socially acceptable physical appearance as female. This is an attempt to overcome the discomfort caused by non-alignment of birth sex with self-identified gender as well as discrimination and rejection. One of the participants shared:

Like for transgendered prostitutes, it's a case of there going to be needing first and foremost-the first drug on that list that they will be wanting would be estradiol spironolactone which are feminizing drugs for transgendered, which are great but outrageously expensive. They are very, very expensive drugs to come by. There is so much money goes into becoming a woman, from the physical attributes that you feel you need because of dysphoria-they are very expensive. So, those would come above anything else.

Another stated: 
And as transgendered it's hard enough for us to live in like normal life.... You know, hormones, you have to shave every day. It a lot of extra work for us to look, and to feel acceptable, on a daily basis. So we have to go through all these extra steps. So adding HIV to all the steps to the steps that I am already taking, it seems like a lot of work. It just seems very tedious. It's not one of those lifestyles that you can't just go about your day and be happy. It's like, wait I have to do all these extra steps. It makes your life more complicated.

\section{Motivators for Acceptability of Preexposure Prophylaxis Therapy}

This cluster theme was defined as the expressed willingness to adopt PrEP as HIV prevention despite condom use.

Use of PrEP for self-protection. Many participants conveyed a willingness to adopt PReP as an HIV prevention method and to be proactive at self-preservation. One participant said:

I am glad that they are making advancements. I think it is very important, you know, that they are funded for the research and it is a very important cause. I know a few people that do suffer from HIV and I know like it is, you know, before, you know, there is a lot of trans women in the community that suffered before like they had the aftercare program, so it is good that they are findings ways to prevent it further...Uhm, if I'm given a prescription of Truvada, I would definitely use it.

Another participant stated:

I will take the medication just in case if anything happens, just in case if I end up slipping up or forgetting or not thinking or if I'm just overwhelmed and just 
worked up, because things happen. So I just want to make sure just in case if anything does happen, I will be prepared for it.

In a final example of this theme, a participant said, "I would take advantage (PrEP)...Because I want to be safe. I not only want to protect myself, I want to protect my partner."

Fear of HIV. Trepidation about contracting HIV through unsafe sex reverberated through participants' narratives of condom use with sexual partners. The fears were based on the loss of a loved one to HIV/AIDS. Participants acknowledged they would avoid contracting the infection when given a choice. A participant said:

I am not really sure. Uhm, to be honest with you I have not really been taking care of myself. Lately I have been kind of in a depression and I've had unprotected sex about twice this week and I am kind of scared that I may have it and I don't really know, I know like the after care has gotten a lot better but I do not know to what extent and it kind of worries me.

Another narrated:

It would be crushing to have the HIV virus, there is a lot of stigma against transgendered people, to be a transgendered person that is HIV positive would exacerbate the issues it would make all the issues much worse. HIV would still be a death sentence at least to me in even just in terms of social or political sense it would suck. In a medical sense it would be awful, it would be horrible. It would be crushing. Well, I don't have sex with anyone unless I know them very intimately. I always wear a condom. I make sure that if I am with anyone that needs a condom, they wear a condom. I try not to engage in high-risk behavior 
because of that fear. That is how I protect myself, is by not getting close to anyone without knowing what they are about, who they are, and basically what their past has been like. I have only had unprotected sex once, and I knew him very well and I trusted him.

Although some used preventive measures with casual partners, many engaged in high-risk sexual behaviors with primary partners. One participant said:

Well, the only way that I would be submissive in that sense is with my boyfriend. Because it is a lot of things, he is very abusive and he is very intimidating. You know it's like just mentioning it would only make him angry. So even if you know that he is HIV positive. Mmhmm, and he doesn't like for me to carry condoms, lubricants or anything in my purse because he assumes I am working or I am out there prostituting.

Another shared:

I have. Uhm not prostitution but like in a way it's kind of like a favor thing with, uhm -- I've had, not anymore, but I've had like a sugar daddy that pays for everything and of course like there are times that he would want to engage with sex and at times I want him to use a condom but he doesn't want to, so we just had to not to, you know like-- But I'm not really like, oh! You know prostituting myself outside, just saying "Oh! I have a price." It's just that before I find one person to kind of take care of me.

\section{Barriers To Acceptability of Preexposure Prophylaxis Therapy}

This cluster theme was based on participants' descriptions of personal protective practices that led them to feel Preexposure prophylaxis therapy were unnecessary. 


\section{Misconception regarding use of PrEP therapy for HIV prevention. Some}

participants had misconceptions about the use of PrEP; some compared it to the of emergency pregnancy pill that is used only when necessary. In one example, a participant stated:

So it was around the same time I met my boyfriend, my ex-boyfriend, but they were calling it prophylaxis. It is, it is prophylaxis! Which I didn't really understand, but I know that was the first thing that popped into my mind when we had unprotected sex and he came inside of me and I was laying there like devastated cause I thought there was nothing I can do about it and I was going to get it. And that was the first thing I said out loud, so I went to the hospital and told them that this is what I needed to do. And they gave it to you. They do the PrEP classes. So I was able to continue to get the Truvada through the clinic. And I had to continually go back every month to get the HIV test done and finally they gave me a prescription of Truvada... I believe it works. In my heart, the only reason I don't have it (HIV) right now is because I have taken it. Even though I have missed a couple days in between, but it's pretty much consistent.

Another shared:

I don't know if I would maybe take it every day but I think that I'd take it maybe like before I have sex or I'll try to take it every day but I know sometimes I'm gonna forget or you know, just no one really keeps up with every day stuff. Sometimes I even forget to take my spironolactone.

Oppositions to use of PrEP. Many participants who expressed a positive opinion regarding PrEP felt uncertainty about the personal adoption of this method to prevent 
HIV. The opposition to adopting PrEP was founded on the lack of available information about drug interactions with required transitional medications. A participant explained as follows:

First, I'd wanna know, like you know, what does this medication do and what are its reactions because you know I am on hormones and I'm taking spironolactone so I, you know, I need to know if that interferes with any of my transition and I need to ask my doctor first because I' $m$ not allowed to take medication without her, her permission 'coz I'm on hormones. But if that would go by then I'd say I would do it. I don't know if I would maybe take it every day but I think that I'd take it maybe like before I have sex or I'll try to take it every day but I know sometimes I'm gonna forget or you know, just no one really keeps up with every day stuff. Sometimes I even forget to take my spironolactone.

Another said:

If I was engaging in high-risk behavior, the thing that would hinder me most would be the convenience. So let's say I was engaging in high-risk behavior like prostitution, or it would have to do with timing. Like in between clients and stuff, you would have to find time to take the drug. Another hindrance would be the financials of it, if I was engaging in this high-risk behavior how am I going to afford something like this. Like for transgendered prostitutes, it's a case of there going to be needing first and foremost-the first drug on that list that they will be wanting would be estradiol spironolactone which are feminizing drugs for transgendered, which are great but outrageously expensive. They are very, very expensive drugs to come by. There is so much money goes into becoming a 
woman, from the physical attributes that you feel you need because of dysphoriathey are very expensive. So, those would come above anything else. It would come above even a drug like PReP, which would be for safety. The question would be how much is this drug, how much are the other drugs costing that is it going to allow even enough leeway, so let's say you have the extra money you are putting it away for your next dose of estradiol spironolactone, that's what you are saving all your money for, it's the urge to have those drugs because they are available overwhelming. It is very, very desirable and very expensive. So that would be hindering the usage of it would be the financial costs. Something that would support it is that is definitely safer, if the stats that you are telling me are definitely accurate, those stats would be very persuasive. It's a big problem in the LGBT community still and there has been so much progress over the years, there is not that much of a problem as it was in the 80 s and 90 s and it would be convincing, those stats.

Lack of desire for PReP. Some of the participants expressed lack of desire for PrEP for moral reasons. One of the participants explained this lack of desire: I mean I don't have a really high sexual behavior, so it really wouldn't -- it will almost be like I'm just taking the pill just to take it even when I'm not really much sexually active. I'm not now in my life, I'm not really sexually active. When I was younger I probably was and I very like you know enjoyed a sexual life, but right now, I'm not really sexually active and that's not what I'm concentrating my time on, so the pill would be just like, you know, I wouldn't even know where to begin to even start taking it because I'm not sexually active like should I take it 
before I have sexual intercourse or should I be taking it regularly and you know I make a guy wait at least 90 days before I even consider sexual intercourse, so it's like that would be a dilemma.

\section{Discussion}

This study focused on the acceptability of PrEP therapy within the context of the lived experiences of MtF-TG young adults. The participants' descriptions of the phenomenon resulted in cluster themes of MtF-TG adults' attributes, the essence of life as MtF-TG, motivators for acceptability of PrEP, and barriers to PrEP acceptability.

The findings confirmed the experience of incongruity related to assigned birth sex based on anatomical genitalia and an affinity to self-identify as the opposite gender as reported from previous research studies. In transgender individuals, there is a feeling of being born in a "wrong body" or incongruence of sex with gender (Alegria, 2011; DHAP, 2011; IOM, 2011). Other findings of this study, including interest in adoption and barriers to acceptability of PrEP are similar to findings from previous research (Brooks et al., 2011; Brooks et al., 2012; Galindo et al., 2012; Yang et al., 2013). Although previous research indicated MtF-TG individuals engage in high-risk sexual behavior (Bullough, 2000; De Santis, 2009), many of the participants in this study used condoms and abstinence. This could be a result of the massive educational campaign on safe sex and condom use; participants stated they received safe sex and HIV prevention education at community organization centers and other venues.

A unique finding in this study was the theme of the essence of life as male-tofemale individuals. Many of the participants articulated the importance of being seen and accepted as a female. Self-validation and acceptance as a woman is paramount to the 
essence of life for an MtF-TG individual. The feeling of being a woman in a man's body is responsible for the experience of chronic stress MtF-TG among individuals. Dysphoria, experiences of rejection, discrimination, and homelessness contribute to poor mental health and suicide attempts (CDC, 2011; Corliss, Goodenow, Nichols, \& Austin, 2011; De Santis, 2009; Garofalo et al., 2006). The process of transitioning to being a woman is viewed as a path to normalcy that ameliorates the discomfort associated with being transgender.

The extent of commitment to physical body alteration is often dependent on level of discomfort with birth sex, and the desire to identify as a female (Alegria, 2011). A challenge MtF-TG individuals face is associated with the cost of required medical and surgical materials. The initial transition process involves injecting hormones. However, due to low education, rejection, and discrimination, many MtF-TG young adults are unemployed and lack financial resources. Previous work supports the fact that up to $61 \%$ of transgender individuals consume feminizing hormones that are obtained illegally (Garofalo et al., 2006). For some transgender individuals, the urgency of transitioning to the opposite gender is such a priority that they would engage in HIV risk behaviors to finance medical costs. Many participants mentioned obtaining their hormones through their physicians and being under the care of both of a health care provider and mental health counselor. They did not disclose if access to health care system was through seeking hormone treatment.

This study has limitations and caution should be exercised with the results. The goal of qualitative phenomenological research is to gain a nuanced "thick" view of a specific human phenomenon. Given the paucity of information about the health needs of 
MtF-TG young adults in general, this study constitutes a first step in addressing a critical health for a vulnerable sexual minority group.

\section{Conclusion and Implications for Nursing Profession}

The findings of this study indicate an opportunity for PrEP therapy education among the MtF-TG young adult population. Accurate information on the use and efficacy of PrEP among the target population is paramount to the goal of HIV prevention. The most important finding is that the essence of being and living as a woman is depicted as more important than the risk of acquiring HIV infection. Many of the participants, while acknowledging the idea of PrEP as HIV prevention, would hesitate to use it for fear of interference with feminizing hormone therapy. Future research on the PrEP interaction with feminizing hormone therapy is essential to acceptance among the MtF-TG young adults. Integration of this concept with previously identified challenges with the implementation of PrEP among MtF-TG young adults would enhance acceptability and ultimately reduce new HIV infection. 


\section{References}

Alegria, C. A. (2011). Transgender identity and health care: Implications for psychosocial and physical evaluation. Journal of the American Academy of Nurse Practitioners, 23, 175-182. Retrieved from http://dx.doi.org/10.1111/j.1745$7599.2010 .00595 . x$

Bith-Melander, P., Sheoran, B., Sheth, L., Bermudez, C., Drone, J., Wood, W., \& Schroeder, K. (2012, May/June). Understanding sociocultural and psychological factors affecting transgender people of color in San Francisco. Journal of the Association of Nurses in AIDS Care, 21(3), 207-220. Retrieved from http://dx.doi.org/10.1016/j.jana2010.01.008

Bockting, W. O., Miner, M. H., Swinburne Romaine, R. E., Hamilton, A., \& Coleman, E. (2013). Stigma, mental health, and resilience in an online sample of the US transgender population. American Journal of Public Health, 103, 943-951. Retrieved from http://dx.doi.org/10.2105/AJPH.2013.301241

Brooks, R. A., Kaplan, R. L., Lieber, E., Landovitz, R. J., Lee, S., \& Leibowitz, A. A. (2011, September). Motivators, concerns, and barriers to adoption of preexposure prophylaxis for HIV prevention among gay and bisexual men in HIV-negativeserodiscordant male relationships. AIDS CARE, 23(9), $1136-1145$. Retrieved from http://dx.doi.org/10.1080/ 09549121.2011.554528

Brooks, R. A., Landovitz, R. J., Kaplan, R. L., Lieber, E., Lee, S., \& Barkley, T. W. (2012). Sexual risk behaviors and acceptability of HIV Pre-Exposure prophylaxis among HIV-negative Gay and Bisexual Men in serodiscordant relationships: A 
mixed methods study. AIDS Patient Care and STDS, 26(2), 87-94. Retrieved from http://dx.doi.org/ 10.1089/apc.2011.0283

Bullough, V. L. (2000). Transgenderism and the concept of gender. International Journal of Transgenderism, 4(3). Retrieved from http://www.wpath.org/journal/www.iiav. nl/ezines/web/IJT/97-03/numbers/symposion/bullough.htm

Center for Disease Control. (2011). National Center for HIV/AIDS, Viral Hepatitis, STD, and TB Prevention: Division of HIV/AIDS Prevention. Retrieved from http://www.cdc.gov/hiv/topics/surveillance/basic.htm\#hivaidsrace

Center for Disease Control. (2012). Retrieved from http://www.cdc.gov/vitalsigns/ HIVAmong Youth/index.html

Center for Disease Control Fact Sheet: PrEP: A new tool for HIV prevention. (2012). Retrieved from http://www.cdc.gov/nchhstp/newsroom/docs/2012/PrEPFactSheet-080912-508.pdf

Center for Disease Control Fact Sheets. (2013). PrEP: A new tool for HIV Prevention. Retrieved from http://www.cdc.gov/nchhstp/newsroom/docs/PrEP-FactSheet508.pdf

Center for Disease Control Vital Signs. (2012). HIV Among Youths in the US: Protecting a Generation. Retrieved from http://www.cdc.gov/vitalsigns/pdf/2012-11-27vitalsigns.pdf

Corliss, H. L., Goodenow, C. S., Nichols, L., \& Austin, S. B. (2011, September). High burden of homelessness among sexual-minority adolescents: Findings from a representative Massachusetts high school sample. American Journal of Public Health, 10I(9), 1683-1689. http://dx.doi.org/10.2105/AJPH.2011.3001551 
De Santis, J. P. (2009). HIV infection risk factors among male-to-female transgender persons: A review of the literature. Journal of the Association of Nurses in AIDS Care, 20(5), 362-372. doi: 10.1016/j.jana.2009.06.005

Division of HIV/AIDS Prevention. (2011). HIV among transgender people. Retrieved from Retrieved from http://www.cdc.gov/hiv/transgender/pdf/transgender.pdf

Galea, J. T., Kinsler, J. J., Salazar, X., Lee, S., Giron, M., Sayles, J. N., ... Cunningham, W. E. (2011). Acceptability of Pre-Exposure prophylaxis as an HIV prevention strategy: Barriers and facilitators to Pre-exposure prophylaxis uptake among atrisk Peruvian populations. International Journal of STD \& AIDS, 22, 256-262. Retrieved from http://dx.doi.org/10.1258/ijsa.2009.009255

Galindo, G. R., Walker, J. J., Hazelton, P., Lake, T., Steward, W. T., Morin, S. F., \& Arnold, E. A. (2012). Community member perspectives from transgender women and men who have sex with men on Pre-exposure prophylaxis as an HIV prevention strategy: Implications for implementation. Implementation Science, 7(116). Retrieved from http://dx.doi.org /10.1186/1748-5908-7-116

Garofalo, R., Deleon, J., Osmer, E., Doll, M., \& Harper, G. (2006). Overlooked, misunderstood and at-risk: Exploring the lives and HIV risk of ethnic minority male-to-female transgender youth. Journal of Adolescent Health, 38, 230-236. Retrieved from http://dx.doi.org/10.1016/j.jadohealth.2005.03.023

Grant, R. M., Lama, J. R., Anderson, P. L., McMahan, V., Liu, A., Vargas, L., ... Glidden, D. V. (2010, December, 30). Preexposure Chemophylasix for HIV prevention in men who have sex with men. The New England Journal of 
Medicine, 363(27), 2587-2599. Retrieved from

http://dx.doi.org/10.1056/NEJMoa1011205

Grossman, A. H., \& D' augelli, A. R. (2006). Transgender youth. Journal of

Homosexuality, 51(1), 111-128. Retrieved from

http://dx.doi.org/10.1300/J082v5In01 06

HIV Among Youths in the US: Protecting a generation. (2012). Retrieved from http://www.cdc.gov/vitalsigns/pdf/2012-11-27-vitalsigns.pdf

Hightow-Weidman, L. B., Phillips11, G., Jones, K. C., Outlaw, A. Y., Fields, S. D., \& Smith, J. C. (2011). Racial and sexual identity-related maltreatment among minority YMSM: Prevalence, perceptions, and the association with emotional distress. AIDS Patient Care And STDs, 25(Supplement 1), S39-S45. Retrieved from http://dx.doi.org/10.1089/apc.2011.9877

Institute of Medicine. (2011). The health of lesbian, gay, bisexual, and transgender people: Building a foundation for better understanding. Washington, DC: National Academies Press.

Kosciw, J. G., Greytalk, E. A., \& Diaz, E. M. (2009, 7 May). Who, what, where, and why: Demographic and ecological factors contributing to hostile school climate for Lesbian, Gay, Bisexual, and Transgender youth. Journal of Youth Adolescence, 38, 976-988. Retrieved from http://dx.doi.org/10.1007/s10964-009$9412-1$

Kuyper, L., \& Wijsen, C. (2013, July 16). Gender identities and gender dysphoria in the Netherlands. Archives of Sexual Behavior. Retrieved from http://dx.doi.org/10. 1007/s 10508-013-0140-y 
Logie, C. H., James, L., Tharao, W., \& Loutfy, M. R. (2011). HIV, gender, race, sexual orientation, and sex work: A qualitative study of intersectional stigma experienced by HIV-positive women in Ontario, Canada. PLoS Medicine, $8(11)$, e1001124. Retrieved from http://dx.doi.org/10.1371/journal.pmed.1001124

Lopez, K. A., \& Willis, D. G. (2004, May). Descriptive versus interpretive phenomenology: Their contributions to nursing knowledge. Qualitative Health Research, 14(5), 726-735. Retrieved from http://dx.doi.org/10.1177/1049732304263638

McBride, D. L. (2012). Homelessness and health care disparities among Lesbian, Gay, Bisexual, and Transgender youth. Journal of Pediatric Nursing, 27, 177-179. Retrieved from http://dx.doi.org/10.1016/j.pedn.2011.11.007

Nemoto, T., Operario, D., Keatley, J., Han, L., \& Soma, T. (2004). HIV risk behaviors among male-to-female transgender persons of color in San Francisco. American Journal of Public Health, 94(7), 1193-1199.

Nemoto, T., Operario, D., Keatley, J., \& Villegas, D. (2004b). Social context of HIV risk behaviors among male-to-female transgender of color. AIDS CARE, 16(6), 724 77. Retrieved from http://dx.doi.org/10.1080/0954012412331269569

Sadala, M. L.A., \& Adorno, R. DE C. F. (2002). Phenomenology as a method to investigate the experience lived: A perspective from Husserl and Merleau Ponty's thought. Journal of Advanced Nursing, 37(3), 282-293.

Sausa, L. A., Keatley, J., \& Operario, D. (2007). Perceived risks and benefits of sex work among transgender women of color in San Francisco. Archives of Sexual Behavior, 36, 768-777. doi: 10.1007/s10508-007-9210.3 
Stevens, R., Bernadini, S., \& Jemmott, J. B. (2013, 26 July). Social environment and sexual risk-taking among Gay and Transgender African American youth. Culture, Health \& Sexuality: An International Journal For Research, Intervention, And Care. Retrieved from http://dx.doi.org/10.1080/13691058.2013.809608

Yang, D., Chariyalertsak, C., Wongthanee, A., Kawichai, S., Yotruean, K., Saokhieo, P., ... Chariyalertsak, S. (2013, October). Acceptability of Pre-Exposure prophylaxis among men who have sex with men and transgender women in Northern Thailand. PLOS ONE, 8(10), e76650. Retrieved from http://dx.doi.org/10.1371/journal.pone.007665 
Running head: IT'S A DEAL BREAKER: SAFE SEX PRACTICE AMONG

\author{
Manuscript \# 3 \\ It's a Deal Breaker: Safe Sex Practice Among Homeless Male-to-Female \\ Transgender Young Adults
}

Gloria Nwagwu MSN, FNP-BC, RN

Hahn School of Nursing and Health Sciences

University of San Diego

Acknowledgement: The researcher expresses gratitude to all the participants for sharing their stories with her. 


\begin{abstract}
Purpose: To describe adoption of safe sex practice within the context of the lived experiences of homeless male-to female transgender (MtF-TG) young adult.

Background: Male-to-Female transgender (MtF-TG) young adults constitute a proportion of the $40 \%$ of homeless sexual minority individuals in Los Angeles County. MtF-TG individuals are frequently displaced from families at early age with disruptions in early childhood development and interruption in the development of the skills necessary for successful adult life. The displacements are often related to gender orientation and nonconformity to the societal accepted binary gender system of male and female. Some homeless MtF-TG individuals engage in high-risk sexual behaviors that contribute to new HIV infection. Despite the challenges of life on the street, some choose safe sex practice.
\end{abstract}

Design/Method: This was a descriptive phenomenological study. The data were collected using semi-structured open-ended interview questions from $15 \mathrm{MtF}-\mathrm{TG}$ young adults living in an emergency shelter and on the street in Los Angeles County. The audiorecorded interviews was transcribed and analyzed using the seven steps of Colaizzi process.

Results: Five main themes were obtained in association to the phenomenon of safe sex practice among homeless MtF-TG young adults living in Los Angeles County: Fear of HIV, setting boundaries, self-protection, and awareness of HIV status and loss of control.

Conclusions: The findings of this study indicate the conscious effort to adopt safe sex practice within the context of the lived experiences of homeless MtF-TG young adults living in Los Angeles County. The driving forces behind decision are associated with prior HIV transmission and prevention, knowledge of individuals dying from HIV/AIDS as well as desire for boundary setting to ensure self-protection from contracting sexually transmitted infections. When confronted with the challenges of partner abuse, financial hardship and rape, some MtF-TG population loose control for desired safe sex practice. Implications for research and practice, in collaboration with organizations caring for homeless MtF-TG young adults, would include designing and providing population targeted sex education aimed at safe sex negotiation skills and HIV-risk prevention Behaviors. Most vulnerable population is those engaged in HIV risk Behaviors with primary sexual partners and in prostitution.

KEYWORDS: Lived experience, male-to-female transgender (MtF-TG) 


\section{Introduction}

The male-to-female transgender (MtF-TG) young adult constitutes a portion of the $40 \%$ of homeless sexual minority individuals living in Los Angeles County (Parr, 2013). Prior studies indicate the MtF-TG young adults frequently experience rejection and discrimination from their family and society for non-conformity to societal accepted binary gender of male and female (Clements-Nolle, Marx, \& Katz, 2006; De Santis, 2009; Garofalo, Deleon, Osmer, Doll, \& Harper, 2006; McBride, 2012). In one study, $48 \%$ of lesbian, gay and bisexual youths were displaced or ran away from home to live in either foster homes or on the streets (Rosario, Schrimshaw, \& Hunter, 2012). Displaced from home and exposed to life in various foster homes, MtF-TG young adults experience disruption in early childhood developmental skills and the acquisition of the skills necessary for successful adult life.

The MtF-TG young individuals experience rejection, discrimination, stigmatization, low-education, unemployment, verbal, physical and sexual abuses, mental health issues. They frequently find solace on the street and many engage in survival sex work in exchange for basic needs (Centers for Disease Control, Division of HIV/AIDS Prevention, 2011; De Santis, 2009). Factors other than unemployment and stress from psychosocial issues contributing to engagement in high risk sexual behavior and HIV risk include substance abuse, low self-esteem, a need for validation, and acceptance of self as "woman" (Sari, Reisner, Perkovich, \& Mimiaga, 2010; Sausa, Keatley, \& Operario, 2007). Engagement in high-risk sexual behavior is not without consequences. Increased rate of new HIV infection among the MtF-TG population has been associated to 
indulgence in high-risk behavior and sex work (Centers for Disease Control, Division of HIV/AIDS Prevention, 201 1; De Santis, 2009; Garofalo et al., 2006). Customers willing to pay more for unprotected sexual act and sex under the influence of drugs as well as willingness to succumb to unsafe sex in hardship situations have been noted to be contributory influences on the high incidence of HIV infection among homeless MtF-TG individuals (Deering et al., 2013).

To date, sex education, risk reduction counseling, and condom use provision and promotion have been adopted to address the HIV infection rate among the sexual minority population. The use of latex condom is effective in HIV and other sexual transmitted infections. Baseline efforts to promote condom use as a method to prevent and decrease the high rate of HIV infection among the MtF-TG population was aimed at individual, peer, and partner factors. However, the structural factor approach to condom distribution as well as availability of condoms for HIV prevention increases condom use (Charania et al., 2011). The structural factor refers to social, legal-political, economical and cultural drivers beyond the individual's understanding and comprehension that escalate vulnerability to HIV risk behavior (Gupta, Parkhurst, Ogden, Aggleton, \& Mahal, 2008). The structural level condom distribution at individual, organization, and community levels to address factors affecting availability of condoms and the dynamics influencing HIV risk behaviors have been instituted (CDC, 2010).

Organizations and homeless shelters working with homeless minority sexually active young adults employ individual and structural level-HIV prevention strategies. HIV prevention counseling regarding HIV infection, method of transition, and latex condoms availability at no cost are routinely provided to these individuals (Ream, 
Barnhart, \& Lotz, 2012). Homeless MtF-TG individuals frequently receive information about safe sex negotiation skills and basic needs of food and shelter to ameliorate financial burden as incentive for engaging in unsafe sex practices. This phenomenological descriptive study was designed to explore the rationale for adopting safe sex practice with in the context of lived the experiences of homeless MtF-TG young adults in Los Angeles County.

\section{Study Design and Methods}

This descriptive phenomenological research was conducted with homeless MtFTG young adults recruited from a shelter in Los Angeles County. A descriptive phenomenology approach was adopted to hold in abeyance the entire researcher's identified personal bias and prior beliefs to capture the meaning of study aims. A purposive sampling was utilized of homeless young adult ages 18-25 years old. Participants self identified as $\mathrm{MtF}-\mathrm{TG}$ in varying stages of transition. Participants were able to communicate in English, and self-report HIV-negative result within the previous 3 months as inclusive criteria for the study. Sampling continued until data saturation was achieved after interviewing 15 participants from January to February 2014. The study was reviewed and approved by the IRB at University of San Diego.

Prior to data collection a research study recruitment posters were disseminated to many community-based organizations and churches working with homeless MtF-TG young adults. Participants were offered $\$ 25$ gift certificate for participation. In addition, online advertisement with the same recruitment information was posted on Craigslist within three Counties in Southern California. Data were collected from one communitybased organization and does not include any other source. The objective and 
significance of the study was reviewed with participants. Prior to data collection where they were informed that participation was voluntary and they were free to withdraw at any point during the study. Participants were informed participation required a willingness to be digitally recorded and informed consent was then obtained from each participant. Ethical considerations were observed by the use of pseudonyms to replace participants' names in the report of the findings.

\section{Interview Protocol}

The researcher sat with each participant in a quiet office prior to data collection to review the study procedures. Participants were informed of freedom to withdraw at any stage of the study. Following verbal consent and answering of participant questions, written consent was obtained. However, names were not used to preserve participants' privacy and anonymity. The researcher then proceeded with the interview process starting with demographic questions of assigned gender at birth, gender identification, housing, employment, and questions related to phenomena of study. The process was continued with prompts to elicit responses addressing other related phenomena like sex under the influence of drugs and having sex for money. Each interview lasted 30-45 minutes and the same protocol was applied to all participants. All recorded data was carefully transcribed verbatim from the digital recorder.

\section{Data Management and Analysis}

Colaizzi (1978) seven-step process of data analysis was employed as follows. The interview audio files and transcribed data were stored in locked safe at the researcher's office. The researchers listened to the audio recorder and re-read the transcripts several times to obtain accurate interpretation of data. Next, phrases and sentences related to the 
phenomenon were extracted and meanings were assigned to formulate concepts. In the next step, concepts were assigned into specific theme categories. The researcher maintained authenticity of content by verifying extracted concepts for accuracy with the participants. Final concepts were aggregated to formulate comprehensive and completed description.

The researcher maintained credibility of the study by engaging in data analysis for a prolonged period and using the participants' words in the final description of the phenomenon of study. Dependability and conformability were ensured as the researcher engaged in an iterative process with the recorded audio file and transcribed data to avoid interjecting personal bias in the meaning of extracted data. Limited prior studies were not reviewed prior to data analysis to avert influence on the results of this study.

\section{Results}

Of the 15 participants, 12 used of condom, 3 participants did not use condoms; 10 participants engaged in sex for money at some point in their life and 5 never engaged in prostitution. The use of Colaizzi's process of data analysis resulted in identification of several themes, which are summarized below.

\section{Fear of HIV/AIDS}

Many of the participants had direct contact or knew someone suffering from or who died of HIV/AIDs. Ten of 12 who self-reported use of condoms cited fear of contracting HIV infection as major incentive for their use. Participants described the thought of contracting HIV infection as follows:

It would be crushing to have the HIV virus, there is a lot of stigma against transgendered people, to be a transgendered person that is HIV positive would 
exacerbate the issues it would make all the issues much worse. HIV would still be a death sentence, at least to me, in even just in terms of social or political sense, it would suck. In a medical sense it would be awful, it would be horrible. It would be crushing.

(Partner was HIV positive). Yea, he told me... Oh yea, I don't know it was... I was scared at first but then I just kinda realized that if we use condoms. Even if we used condoms I was nervous, having sex with him for the first time. Some participants felt HIV infection represented an obstacle to an already complicated life as a sexual minority individual. In response to what having HIV would mean, participants shared the following:

If I have a HIV now, of course, I'd be scared but at the same time I'm not really the type who makes a big deal out of anything so you know I wouldn't let me-- it wouldn't bring me down but you know like it would be just like bummer you know. But you know thank God like I haven't gotten it. So that's why I'm trying to like practice safer sex and not even having sex at all.

I am not really sure. Uhm, to be honest with you I have not really been taking care of myself. Lately I have been kind of in a depression and I've had unprotected sex about twice this week and I am kind of scared that I may have it and I don't really know, I know like the after care has gotten a lot better but I do not know to what extent and it kind of worries me.

One of the participants saw HIV infection being associated with poor judgment stating: I would never want to have HIV. Like I mean I would, you know, I know some people who have it around here and I've asked them like how did you catch it, 
and they were like well I was just sleeping around with so and so on. You know sleeping with all of these random men... And like I was just like, well shit, like as long as I don't sleep with random men apparently, I'm like, I won't catch it, right. Many participants had opportunities to receive safe sex education and free condom program offered to homeless MtF-TG young adults. Hence, contracting HIV was viewed as an intentional reckless behavior versus lack of knowledge of HIV prevention. A participant stated the following:

And I've dated partners who've had it and I've had so many classes saying that -cause I've had so much training with it. You know what I'm saying like even -even when we were in middle school, we had sex ed -- and sex class here, but l've had so many classes before that actually breaks it down for you like the steps and shows you what it looks like and what the fat muscles look like and all that and I have to question everything like even before I start dating someone. I am a very picky person, very picky when it comes to dating people. For dating men, I am very picky... It would be very sad for me because I wouldn't want to do it. I wouldn't want to go through with it, you know. I wouldn't say life would be unlivable but it still is livable. But it would just be hard... No, I don't want to destroy my life at all. It's like, it comes with -- it comes with a burden, you know. You don't -- you don't want to carry that kind of burden with you.

\section{Setting Boundaries}

Some of the participants, especially those involved in prostitution, expressed strong predisposition for condom usage even at the risk of financial loss. The 
appreciation for health and ability to exercise self-control was viewed as being more important over a short-lived relationship or moment of pleasure.

Um, yea for others maybe, for me it's just me being careful. Me being cautious. And wearing a condom is an easy deal breaker, unless of course... Not wearing a condom is a deal breaker. There is no $\$ 20$ extra or $\$ 40$ extra that would do it... no, cause just because I am not catching the HIV strain from my partner doesn't mean I can't catch it from another. Cos there are different strains of HIV. I treat everyone like they have a virus. That's how I was taught, which is protect yourself. That's what I do... Use a condom. And if they don't want to use a condom, then I am not doing nothing at all. I don't care how much money you give me.

It is not worth it means having sex out there, trying it with random different guys or, you know, me not knowing them, I do not know what they have, I'm risking it. It's a high risk, I mean risking it of having sex or not. Not anymore.

\section{Self Protection}

Participants discussed adoption of condom use based on previously acquired knowledge regard self-protection against sexually transmitted infection and HIV. They said:

Well, I don't have sex with anyone unless I know them very intimately. I always wear a condom. I make sure that if I am with anyone that needs a condom, they wear a condom. I try not to engage in high-risk behavior because of that fear. That is how I protect myself, is by not getting close to anyone without knowing what they are about, who they are, and basically what their past has been like. I have 
only had unprotected sex once, and I knew him very well and I trusted him. They had never engaged in sex before so I was ok, in that very select circumstance so I thought it was pretty safe. It is something that they do teach in school. They really drill it into people that these things that can happen to you are real and that you should really protect yourself so I have been really lucky to have been educated in that regard.

I treat everyone like they have a virus. That's how I was taught, which is protect yourself. That's what I do... Use a condom. And if they don't want to use a condom, then I am not doing nothing at all. I don't care how much money you give me.

Some participants spoke of assuming responsibility to ensure safety and selfprotection by being mindful at all times. They shared:

Just like wear a condom. Just be like extra careful and then like be sure that you are aware of what's going on in the situation. Just cause there are people out there that are really crazy and will try to like do really crazy things to like bring your life down. As far as getting HIV and stuff, I mean you gotta make sure the condom is on and it's not ripped. To make sure that you keep yourself protected... Yea! I mean when you're not looking they can take it off, or rip a hole, like yea there are some crazy things they do. SO you have to make sure that there is nothing going on like you know.

Uhm, since I've come to the center ... like there are a lot of HIV groups so I definitely become really educated about it and I think that it's not good but I mean I don't have any sort of negative sigma around it, I don't see it as something bad 
necessarily, like I don't look down on it or anything. I think that it's a disease and like any disease, it's not a good thing to have. You know, it's out there.

\section{Know Your HIV Status}

Another important aspect of safe sex practice is awareness of HIV sero-status through HIV testing. The participants emphasized the personal responsibility of getting tested, sharing HIV status, and requesting a partner's HIV status through testing as essential steps toward safe sex practice. The mentioned:

Uhm, I would like to talk to him like okay-- like I know I like you and all that and I'm like ready to like do stuff but I want to know if we could to -- to the clinic and get like a free HIV test, like maybe we can go to the center and you know, and hopefully if he's like cool, we could go and do that... If he's not cool, well I mean I guess if he's not cool, then I guess it can't happen, you know. So you just got to wait on the right guy. He's just not the right guy for me then.

I get tested and uhm, I always use a condom. There may be, uhm, some high risk things before that and of course, but I always use a condom because no one"s going to tell you, well most of the time guys won't say I'm positive. They always say no I' $m$ not and like -- then you're sitting there wondering.

One participant said, "Because we would go, I would ask him to go with me to the clinic and get tested... Until he got tested and showed me like this is what's up..."

The only participant that works for the entertainment industry spoke of efforts by the organization to promote safe sex practice on the job:

Well, we get tested. The industry is very like safe in that regards. You -- you're always being tested. They test you for everything before you enter the film, so it's 
not like a promiscuous or just monogamous thing. You actually have to get tested in order to be in the industry.

\section{Loss of Control}

Some participants experienced loss of control despite their knowledge and desire to adopt safe sex practice. In cases of sexual or verbal abuse, violence, and injury mostly from primary partners but sometimes in rape situations, participants succumbed to unprotected sex to preserve their safety. They explained as follows:

(Partner Is HIV positive). Well, the only way that I would be submissive in that sense is with my boyfriend. Because it is a lot of things, he is very abusive and he is very intimidating. You know it's like just mentioning it would only make him angry... Mmmh, and he doesn't like for me to carry condoms, lubricants or anything in my purse because he assumes I am working or I am out there prostituting. But I tell him, they are for us. It's a lot of psychological reverse you know what I mean, with him. He says that he is not opposed to using them, but he is opposed to me carrying them so it's like a contradiction.

One participant discussed abandonment of safe sex practice for fear of losing financial support from primary partner:

I have. Uhm not prostitution but like in a way it's kind of like a favor thing with, uhm -- I've had, not anymore, but I've had like a sugar daddy that pays for everything and of course like there are times that he would want to engage with sex and at times I want him to use a condom but he doesn't want to, so we just had to not to, you know like-- But I'm not really like, oh! You know prostituting 
myself outside, just saying "Oh! I have a price." It's just that before I find one person to kind of take care of me.

\section{Discussion}

The purpose of this study was to describe the reasons for choosing safe sex practice among the homeless MtF-TG young adults living in Los Angeles County. One of the findings of this study is previous knowledge of HIV transmission and prevention was paramount to motivation for adaption of safe sex practice. Most of the participants admit to exposure to HIV prevention programs aimed at bridging individual HIV risk in the form of HIV testing drives, safe sex education, and information on HIV/AIDS infection as well as strategies for safe sex negotiation. The adopted safe sex practices were obvious from the themes arising from the findings of this study.

\section{Fear of HIV}

Most of the participants in this study had knowledge of someone with HIV/AIDS infection. Although there is no valid tool for data collection on gender other than the binary male and female, studies indicate a high rate of HIV infection among MtF-TG population based on self-indication (CDC, 2011). The surveillance data in New York from 2005-2009 indicated $95 \%$ of the 206 new HIV cases were MtF-TG women. The MtF-TG individuals frequently experience discrimination, stigma, isolation, and economic marginalization that predispose them to HIV risk behavior in exchange for money. The previous knowledge of friends and acquaintances with HIV infection precludes adoption of safe sex practices among MtF-TG young adults. 


\section{Setting Boundaries}

The MtF-TG population is often victims of stigma and discrimination related to their sex orientation. Many experience alcohol and drug abuse, unemployment, and engage in survival sex. Unsafe sex practices have been linked to alcohol and drug use, and the willingness of sexual customers to pay more for unprotected sex. As a result of economic hardship, some MtF-TG young adults engage in sex for money with risk of HIV and other sexual transmitted diseases (De Santis, 2009; Garofalo et al., 2006; Nemoto, Operario, Keatley, \& Villegas, 2004). Some MtF-TG individuals that are knowledgeable in HIV/AIDS, violence, the risk of high-risk behavior under the influence of alcohol and drugs would opt for safe sex practice that included setting boundaries. The boundary setting practice involved screening clients, being aware, alert and assuming control of the sexual encounter with clients. Others resolved against unprotected sex irrespective of financial hardship or temptation of the remuneration for high-risk sexual behavior. The desire for protection from HIV resonated as a strong indication for safe sex practice. Many of the participants established personal boundaries for safe sexual engagement involving condom usage, especially for those involved in sex for money. In the word of one the participants, "Not wearing a condom is a deal breaker. There is no $\$ 20$ extra or $\$ 40$ extra that would do."

\section{Self Protection}

The fear of contracting HIV and sexually transmitted infections was a mainspring for safe sex practice. The findings from this study indicated an increased interest and use of condom. This is consistent with previous findings where $65 \%$ of participants used condoms for HIV protection (Brooks et al., 2011). In another study that examined $40 \%$ of 
homeless youth with a history of previous sexual activities in the recent past, the finding showed $61 \%$ was engaged in use of condom (Rice et al., 2013).

\section{Awareness of HIV Status}

In conjunction with condom use was the theme of getting tested as an adjunct to self-protection. In this study, participants that adapted safe sex practices insisted on knowing the HIV status of their partners prior to any sexual act as a form of selfempowerment at a perceived chance of contracting HIV. This finding is very fundamental to HIV prevention especially among ethnic minority MtF-TG population that has been reported to be sero unaware and is reluctant to get tested (CDC, 2011).

\section{Loss of Control}

The finding of this study demonstrates that in certain situations, some MtF-TG individuals would abandon safe sex practices in spite of adequate knowledge of HIV risk. The individuals tend to loss control in such condition as customers demanding unprotected sex for higher pay. This theme is consistent with previous findings indicating participants accepted more money for unprotected sex among street and off street sex worker (Deering et al., 2013). Other situations contributing to loss of control among MtF-TG include engaging in unsafe sex with primary partner for fear of violence, abuse, or intimidation; fear of losing a relationship or being alone; fear for personal safety, and a way of extricating the primary partner from others (Ream et al., 2012).

The limitations of this study are in the method and the participants' characteristics. While the descriptive phenomenology is a suitable method for the topic and the sample size, the findings are only transferrable to participants of similar characteristics and so should be interpreted with caution. 
The result of this study indicated perceived HIV vulnerability and desire for selfprotection are suggestive rational for adoption of safe sex practice among homeless MtFTG young adults living in Los Angeles County. To achieve their goals, many set ethical boundaries and insisted on knowledge of their partners' HIV sero-status. There is a group of vulnerable homeless MtF-TG engaging in high-risk sexual behavior with primary partners and others that pay for sex who would fore go sex practice to avoid violence, abuse, and personal safety.

\section{Implications of the Study}

Previous studies have shown the MtF-TG population has the highest rate of new HIV infection (CDC, 2011; Garofalo et al., 2006). Factors such as stigma, homophobia, discrimination have been unemployment, homelessness have been linked to high risk sexual behaviors. Individual adoption of safe sex practices is likely to decrease the new rate of HIV infection among this vulnerable population and subsequently improvement of public health. Recently, a shift to embrace structural level prevention strategies aimed at addressing social, cultural, policy, and economical circumstances that heighten HIV-risk behaviors among MtF-TG individuals is being advocated (Gupta, Parkhurst, Ogden, Aggleton, \& Mahal, 2008). The success of this strategy is dependent on full commitment of all community based organizational agencies, state, national, and health providers to embrace structural level HIV prevention plans. However, future research study is needed to assess the effectiveness of the structural level approach to HIV prevention. In addition, there is need for research directed at HIV information awareness, HIV prevention, and public health implications of HIV infection among the customers of MtF-TG sex worker. 
Previous studies have shown that social, cultural, legal, and economical circumstances heighten experiences of discrimination, homophobia, isolation, alcohol and drug abuse and economic hardship (Logie, James, Tharao, \& Loutfy, 2012). The findings of this study arguments previous works and emphasize opportunity for policy changes to minimize the over arching influence of socio-ecological environment of MtFTG population. Although some progress is being made toward gender equality and LGBT are permitted to some rights including marriage in some states, continued effort need be devoted to policy changes geared toward maximizing gender equality and minimizing discrimination due to gender identification and sexual orientation. 


\section{References}

Brooks, R. A., Kaplan, R. L., Lieber, E., Landovitz, R. J., Lee, S., \& Leibowitz, A. A. (2011, September). Motivators, concerns, and barriers to adoption of Preexposure prophylaxis for HIV prevention among gay and bisexual men in HIV-negativeserodiscordant male relationships. AIDS CARE, 23(9), $1136-1145$. http://dx.doi.org/10.1080/09549121.2011.554528

Centers for Disease Control. (2010). Condom distribution as a structural level intervention. Retrieved from http://www.cdc.gov/hiv/pdf/prevention_programs_ condom_distribution.pdf

Charania, M. R., Crepaz, N., Guenther-Gray, C., Henny, K., Liau, A., Willis, L. A., \& Lyles, C. M. (2011). Efficacy of structural-level condom distribution intervention: A meta-analysis of U.S. and International studies, 1998-2007. AIDS Behavior, 15, 1283-1297. http://dx.doi.org/10.1007/s10461-010-9812-y

Clements-Nolle, K., Marx, R., \& Katz, M. (2006). Attempted suicide among transgender persons. Journal of Homosexuality, 5I(3), 53-69. http://dx.doi.org/10.1300/J082v51n03 04

De Santis, J. P. (2009). HIV infection risk factors among male-to-female transgender persons: A review of the literature. Journal of the Association of Nurses in AIDS Care, 20(5), 362-372. http://dx.doi.org/10.1016/j.jana.2009.06.005

Deering, K. N., Lyons, T., Feng, C. X., Nosyk, B., Strathdee, S. A., Montaner, J. S., \& Shannon, K. (2013, August). Client demands for unsafe sex: The socioeconomic risk environment for HIV among street and off-street sex workers. Journal of 
Acquired Immune Deficiency Syndromes, 63(4), 522-531.

http://dx.doi.org/10.1097/QAI.0b013e3182968d39

Garofalo, R., Deleon, J., Osmer, E., Doll, M., \& Harper, G. (2006). Overlooked, misunderstood and at-risk: Exploring the lives and HIV risk of ethnic minority male-to-female transgender youth. Journal of Adolescent Health, 38, 230-236. http://dx.doi.org/10.1016/j.jadohealth.2005.03.023

Gupta, G. R., Parkhurst, J. O., Ogden, J. A., Aggleton, P., \& Mahal, A. (2008). Structural approach to HIV prevention. Lancet, 372, 764-75. http://dx.doi.org/10.1016/S140$6736(80) 60887-9$

HIV infection among Transgender people. (2011). Retrieved from www.cdc.com

Logie, C. H., James, I., Tharao, W., \& Loutfy, M. R. (2012). "We don't exist”: A qualitative study of marginalization experienced by HIV-positive lesbian, bisexual, queer and transgender women in Toronto, Canada. Journal of the International AIDS Society, 15(17392). http://dx.doi.org/10.7448/IAS.15.2.17392

McBride, D. L. (2012). Homelessness and health care disparities among Lesbian, Gay, Bisexual, and Transgender Youth. Journal of Pediatric Nursing, 27, 177-179. http://dx.doi.org/10.1016/j.pedn.2011.11.007

Nemoto, T., Operario, D., Keatley, J., \& Villegas, D. (2004). Social context of HIV risk behaviors among male-to-female transgenders of color. AIDS Care, 16, 724-735.

Parr, M. M. (2013). Homeless sexual minority youths: An overview for the nurse practitioner. The Journal of Advanced Nursing Practitioner, 12(1). Retrieved from http://ispub.com/IJANP/12/1/2937 
Ream, G. L., Barnhart, K. F., \& Lotz, K. V. (2012). Decision process about condom use among shelter-homeless LGBT youth in Manhattan. AIDS Research and Treatment, 659853. http://dx.doi.org/10.1155/2012/659853

Rice, E., Barman-Adhikari, A., Rhoades, H., Winetrobe, H., Fulginiti, A., Astor, R., \& Kordic, T. (2013). Homelessness experiences, sexual orientation, and sexual risk taking among high school students in Los Angeles. Journal of Adolescent Health, 52, 773-778. http://dx.doi.org/10.1016/j.jadohealth.2012.11.011

Rosario, M., Schrimshaw, E. W., \& Hunter, J. (2012, January). Risk factors for homelessness among Lesbian, Gay, and Bisexual youths: A developmental Milestone approach. Children and Youth Services Review, 34(1), 186-193. http://dx.doi.org/10.1016/j.childyouth.2011.09.016

Sari, L., Reisner, M. A., Perkovich, B., \& Mimiaga, M. J. (2010). A mixed methods study of the sexual health needs of New England transmen who have sex with nontransgender men. Aids Patient Care and STDs, 24(8), 501-513. doi: 10.1089/apc.2010.0059

Sausa, L. A., Keatley, J., \& Operario, D. (2007). Perceived risks and benefits of sex work among transgender women of color in San Francisco. Archives of Sexual Behavior, 36, 768-777. doi: 10.1007/s10508-007-9210.3 


\section{Discussion and Recommendation}

The assumptions made during this dissertation work are described next. Transgender individuals are subjected to life-long stress associated with the notion that being different from the societal binary gender of female and male is wrong. Transgender individuals experience verbal, physical, and sexual abuse, stigma, and discrimination from family, peers, and community. Transgender young adults experience homelessness resulting from rejection and displacement from home and foster systems. Transgender young adults engage in HIV risk behaviors. The findings of this study reveal many transgender young adults are homeless and experience lifelong stressors associated with gender identity and gender expression. Consequently, a minority of MtF-TG youths with strong family, peer, and community support meet the challenges posed by gender dysphoria, and achieve a well-adjusted early adulthood.

Many of the participants in this study shared some of the attributes of transgenderism including the inner recognition of a difference between birth sex and self identified gender an early age. This is a public health issue because parents can be educated to recognize and support vulnerable children during the most critical developmental age to facilitate transition decisions. Many parents lack knowledge about transgenderism and the societal stigma and homophobia associated with gender variant individuals. As such, they fail to protect and support the children. Many young adults are compelled to conform to the norm or abandoned for lack of conformity to the social system that shares same dilemma as the parents. MtF-TG young adults fend for themselves on the streets and in shelters where they continue to experience isolation, discrimination, stigmatization, and lack opportunity for financial support. 
One of the findings of this study was the theme the essence of the MtF-TG. The participants emphasized the important of being recognized as a female. Being a woman is the core of who they are so much so that many would choose feminizing hormone over PrEP therapy. This finding is essential for public health, health care providers, and future researchers working with the MtF-TG population. Successful implementation of PrEP among the MtF-TG population must embrace the central process of transitioning to enhance acceptability. Future research is needed concerning interaction of PrEP with feminizing drugs.

Many MtF-TG young adults at some point in their life engaged in sex for money to meet basic needs. As a result of low or no education, many engage in HIV risk behaviors including prostitution. The findings of this study revealed another contributory factor to HIV risk was sexual customers' willingness to pay more for unprotected sex with these individuals. Although many participants reported testing HIV negative in the 3 months prior to the study interview, some engaged in unprotected sex for money since the HIV test due to financial hardship. The HIV risk behavior of MtF-TG sex workers' sex partners affords opportunity for HIV prevention education as well future research on safe sex negation skills.

Contrary to previous research studies, findings from this study indicate some MtF-TG young adults use safe sex practices. Participants from this study spoke of using condoms and boundary setting as methods of protecting themselves from HIV infection. Many encountered friends, peers, and acquaintances with HIV/AIDS as well exposure to HIV prevention programs. The fear of contracting HIV infection was reported as a strong motivation for condom use, frequent HIV testing, and abstinence. This presents 
opportunity for policy changes to support structural level HIV prevention programs and future research on the best approach to adoption of safe sex practices.

\section{Strengths and Limitations}

A phenomenological design provided an understanding of the lived experiences of HIV negative MtF-TG young adults' acceptability of PReP therapy. Data from the study would augment existing methods for planning a targeted population approach for the implementation of PrEP among MtF-TG young adults.

Limitations of this study include the limited generality of the findings, as the sample excluded non-MtF-TG, female to male transgender individuals, and men who have sex with men, as well as anyone that is HIV positive. Nevertheless, qualitative phenomenological research is by nature designed to gain a nuanced, "thick" view of a specific human phenomenon. Given the paucity of information about the health needs of MtF-TG young adults in general, this study constitutes a first step in addressing a critical health need in an extremely vulnerable population.

\section{Implications}

The findings of this study have future research and public health implications. In the area of research, a part of this study relating to attributes and life long stresses of MtF-TG individuals supports previous studies, but there is need for further research to examine the drug interaction of PrEP with feminizing hormones. Further research is needed in the area of barriers and facilitators of condom use to enhance adoption of safe 
sex practices and decrease the incidence of new HIV infection among the MtF-TG population.

In the area of practice, there is need to educate the sex partners of MtF-TG sex workers about HIV infection and transmission to minimize unprotected sex. There is need for collaboration between health care providers and community-based organizers working with MtF-TG population to implement safe sex negotiation skills and engage sex partners in HIV prevention programs.

In the area of health policy, findings from this study offer opportunity for policy changes to minimize societal stigma and homophobia associated with transgenderism. Although transgender individuals are more visible and actively involved in the society, it has been through the advocacy of the transgender community. More is needed at the local, state, and national levels to implement policy changes that will positively enhance the health needs of the gender variant and sexual minority population. 
Appendices 


\section{Appendix B: Participant Consent Form}

Directions to the researcher: fill in shaded portions with your details. Before submitting this form with your application, delete all instructions/sample language and shading. The form MUST appear exactly as participants will see it.

\section{University of San Diego Institutional Review Board}

\section{Research Participant Consent Form}

For the research study entitled: A phenomenological study of HIV negative male-tofemale transgender youths and acceptability of Preexposure prophylaxis therapy

\section{Purpose of the research study}

Gloria Nwagwu is a student in the Hahn's school of Nursing at the University of San Diego. You are invited to participate in a research study she is conducting. The purpose of this research study is: To explore current perceptions regarding HIV prevention, HIV testing, used HIV prevention practices, and knowledge of pre-exposure prophylaxis therapy, and potential acceptability of pre-exposure prophylaxis therapy (PrEP).

\section{What you will be asked to do}

If you decide to be in this study, you will be asked to: Complete one questionnaire that ask you questions about your age, sex/gender, sex assigned at birth, ethnicity, level of education, current employment status, health insurance and access to health care.

Participate in a private interview discussion about safer sex and current methods used to prevent HIV infection. Knowledge of PrEP and what reasons would make it easy to use or not to use PrEP pills for HIV prevention.

You will be audiotaped during the interview and later the interview will be transcribed for analysis.

Your participation in this study will take a total of $30-45$ minutes.

\section{Foreseeable risks or discomforts}

This study involves no more risk than the risks you encounter in daily life.

\section{Benefits}

While there may be no direct benefit to you from participating in this study, the indirect benefit of participating will be knowing that you helped researchers better understand the likelihood to use or not use daily Preexposure prophylaxis therapy pill among male-tofemale transgender youths for HIV prevention.

\section{Confidentiality}

Any information provided and/or identifying records will remain confidential and kept in a locked file and/or password-protected computer file in the researcher's office for a minimum of five years. All data collected from you will be coded with a number or pseudonym (fake name). Your real name will not be used. The results of this research project may be made public and information quoted in professional journals and 
meetings, but information from this study will only be reported as a group, and not individually.

\section{Compensation}

If you participate in the study, the researcher will give you a $\$ 20.00$ gift care in the following way: personally.

You will receive this compensation even if you decide not to complete the entire interview session or not fill out the questionnaire.

\section{Voluntary Nature of this Research}

Participation in this study is entirely voluntary. You do not have to do this, and you can refuse to answer any question or quit at any time. Deciding not to participate or not answering any of the questions will have no effect on any benefits you're entitled to, like your health care, or your employment or grades. You can withdraw from this study at any time without penalty.

\section{Contact Information}

If you have any questions about this research, you may contact either:

(You MUST fill in two contacts and BOTH email and phone).

1) (Name of Principal Investigator) Gloria Nwagwu

Email: gnwagwu@sandiego.edu

Phone: 310-908-0601

2) (Name of Additional Contact) Dr. Jane Georges

Email: jgorges@sandiego.edu

Phone: 619-260-4566

I have read and understand this form, and consent to the research it describes to me. I have received a copy of this consent form for my records. 


\section{Appendix C: Recruitment Flyer \\ VOLUNTEERS NEEDED FOR A RESEARCH STUDY}

A doctoral study is being conducted by a nursing doctorate STUDENT entitled:

"A phenomenological study of HIV negative male-to-female transgender youths and acceptability of Preexposure prophylaxis therapy"

Male-to-Female transgender youths that are HIV negative are needed as research

participants. The participation will be completely voluntary and confidential.

Please respond if you are:

- 18-25 years old

- Self identify as male-to-female transgender, Transwoman

- Are interested in being interviewed for about your lived experience as male-tofemale transgender youth.

- Self-reported HIV-negative result within the previous three months

If the above criteria applies to you and you are interested to be part of this study, please contact the student researcher Gloria Nwagwu at 310-908-0601 and leave your name, phone number, best days and times to reach you. Or via email:

gloria_nwagwu@yahoo.com.

Accepted candidates will be involved in a 30-45 minutes interview and will receive compensation $\mathbf{\$ 2 0}$ gift card for your participation in this study 
Appendix D: Qualitative Interview Questionnaires: Structured and Unstructured

\author{
Hahn School of Nursing and Health Sciences \\ San Diego University \\ Guided Interview Questionnaires
}

A phenomenological study of HIV negative male-to-female transgender youths and acceptability of Preexposure prophylaxis therapy

\title{
Structured Interview Guide
}

As you know from the information sheet, I am interested in your knowledge of and likelihood to use or not use Pre-Exposure Prophylaxis therapy, also known as PrEP for HIV prevention.

To begin our conversation

1. First, would you tell me your age?

2. How would you describe your ethnicity?

3. How would you describe your religion?

4. What was your sex at birth?

5. How would you describe your gender identity?

6. How would you describe your sexual identity?

7. What was the highest level of education you achieved?

8. Are you currently employed? What is your job or profession?

9. Do you currently have health insurance? Is it a group plan through your employer, an individual plan you purchased yourself, or a public plan?

\section{Unstructured Interview Guide}

(Remember, everything you say in this interview will be kept confidential, and no identifying information about you will appear in any transcript or report.)

10. What are some things a person can do to prevent HIV?

11. I'd like to know what you think about preventing HIV. 
12. Would you be willing to tell me how you would assess your risk for HIVinfection?

13. Can you say more about why you think you are [low/moderate/high] risk for HIV?

14. Tell me about some specific things you do personally to prevent HIV.

15. Tell me about getting tested for HIV- what has been your experience with that?

16. Follow-up with: What things keep you from getting tested, or what things make it easier for you to get tested?

17. Tell me about the times you had sex for money

18. Have you ever heard of a pill known as PrEP you take everyday that can prevent HIV?

19. Follow-up with: What did you hear about it? Who was talking about it, or where did you see it?

20. If you could get a pill to take everyday that would protect you from HIV, what would that be like for you?

21. What things would make it easier for you to take an HIV protection pill-for example, if you could get it for free?

22. Follow-up with: What other things would make it easier?

23. What things would make it harder for you to take an HIV protection pill every day?

24. Is there anything else you would like to share with me? Do you have any questions for me about PrEP? Do you have any questions for me about this study? 